\title{
Shear-friction behaviour on smooth interface between high-strength and lightweight concrete
}

\section{Zhuangcheng Fang}

PhD candidate, School of Civil and Transportation Engineering, Guangdong University of Technology, Guangzhou Higher Education Mega Center, Guangzhou, China

\section{Haibo Jiang}

Professor, School of Civil and Transportation Engineering, Guangdong University of Technology, Guangzhou Higher Education Mega Center, Guangzhou, China (corresponding author: hbjiang@gdut.edu.cn)

\section{Airong Liu}

Professor, Guangzhou University-Tamkang University Joint Research Center for Engineering Structure Disaster Prevention and Control, Guangzhou University, Guangzhou Higher Education Mega Center, Guangzhou, China

\author{
Jiahui Feng \\ MPhil candidate, School of Civil and Transportation Engineering, \\ Guangdong University of Technology, Guangzhou Higher Education \\ Mega Center, Guangzhou, China \\ Yuhong Li \\ MPhil candidate, School of Civil and Transportation Engineering, \\ Guangdong University of Technology, Guangzhou Higher Education \\ Mega Center, Guangzhou, China
}

This study presents the results of ongoing research to investigate the shear-friction behaviour of the interface between high-strength (HS) concrete and lightweight (LW) concrete by conducting tests on 18 push-off specimens with a smooth interface condition. The primary parameters considered are the compressive strength of LW concrete and clamping stress through the shear interface. Together with test data from previous studies, the experimental results indicate that both LW concrete strength and clamping stress have an influence on interface shear capacity. Furthermore, an analytical model for predicting the ultimate resistance of the interface between HS and LW concrete is proposed, and the feasibility of this modified equation verified by the experimental results from related references.

\section{Notation}

$A_{\mathrm{c}}$

area of the shear plane $\left(\mathrm{mm}^{2}\right)$

$A_{\mathrm{vf}} \quad$ total area of shear reinforcements $\left(\mathrm{mm}^{2}\right)$

$c \quad$ nominal concrete component

$c_{0} \quad$ cohesion coefficient

$E_{\mathrm{c}} \quad$ modulus of elasticity (MPa)

$E_{\mathrm{s}} \quad$ elastic modulus of shear reinforcement (MPa)

$f_{\mathrm{c}}^{\prime} \quad$ cylinder concrete compressive strength (MPa)

$f_{\mathrm{t}} \quad$ splitting tensile strength (MPa)

$f_{\mathrm{y}} \quad$ yield strength of reinforcement $(\mathrm{MPa})$

$K_{1} \quad$ fraction of concrete strength available to resist smooth interface shear

$K_{2} \quad$ limitation for smooth interface shear resistance (MPa)

$K_{3} \quad$ fraction of concrete strength available to resist rough interface shear

$K_{4} \quad$ limitation for rough interface shear resistance (MPa)

$k \quad$ roughness constant

$v \quad$ interface shear stress (MPa)

$v_{\text {ec }} \quad$ experimental cracking shear stress (MPa)

$v_{\text {Equation }(x)}$ theoretical value calculated by Equation ( $x$ ) (MPa)

$v_{\mathrm{er}} \quad$ experimental residual shear stress (MPa)

$v_{\mathrm{eu}} \quad$ experimental ultimate (peak) shear stress (MPa)

$v_{n} \quad$ experimental shear stress (MPa)

$w \quad$ width of interface crack

$\alpha \quad$ coefficient for bond and interlock action component

$\alpha_{0} \quad$ coefficient for interface condition

$\beta \quad$ coefficient for clamping stress component

$\Delta$

$\begin{array}{ll}\varepsilon_{\mathrm{s}} & \text { measured reinforcement strain } \\ \lambda & \text { correction factor related to concrete density } \\ \mu & \text { friction factor } \\ \rho & \text { interface shear reinforcement ratio }\end{array}$

\section{Introduction}

\section{Background}

Composite beams, made with precast high-strength (HS) concrete girders and cast-in-place lightweight (LW) concrete slabs, are widely used in bridge engineering. This novel construction not only combines the advantage of precast concrete girders and LW concrete slabs, but also retains the efficiency and continuity of monolithic construction. Several studies have found that composite beams have the potential to fail in horizontal shear, which results in the loss of monolithic action and significant reduction of stiffness and flexural capacity (Hanson, 1960; Kahn and Slapkus, 2004; Loov and Patnaik, 1994). However, relatively few studies have investigated the direct shear transfer of HS and LW concrete composite structures with smooth interfaces. This experimental research was intended to extend studies on the shear-friction concept to the shear behaviour of HS and LW concrete composite constructions and to validate the applicability of the existing shear-friction equation. A more accurate modified equation will be proposed in this research to predict the shear stress of interfaces between HS and LW concrete. Additionally, this study is the only known study of shear-friction behaviour 
on smooth interface conditions between HS concrete and LW concrete.

\section{Previous research}

The horizontal shear behaviour of a composite beam interface with large slips and separation can be predicted by the shearfriction concept, which was based on the simplified model originally proposed by Birkeland and Birkeland (1966) and is shown in the schematic representation in Figure 1. The concrete segment on one side of the shear interface tends to slip relative to the other under the shear force, resulting in a deformation, $\Delta$. This deformation will develop a 'wedging action' and force the shear crack to dilate, causing the 'clamping force' $\left(A_{\mathrm{vf}} f_{\mathrm{y}}\right)$ that is generated with the reinforcement crossing the crack plane. This mechanism was aimed at recognising the complex behaviour of shear interfaces, including the friction between two sliding faces, and the resistance offered by aggregate interlock action, which originates from the clamping force caused by shear reinforcement across the shear plane. However, along the smooth construction joint, little aggregate interaction can be expected, and thus almost all of the shear transfer capacity of the concrete component depends on the concrete cohesion. The shear-friction concept was evaluated and verified extensively by push-off tests using the parameters of interface preparation, reinforcement ratio and concrete strength (Hofbeck and Ibrahim, 1969; Kriz and Raths, 1965; Mattock and Hawkins, 1972; Paulay et al., 1974).

Mattock (1974) and Mattock et al. (1975) performed an experimental and analytical study on the influence of the arbitrary angle of shear reinforcement to shear plane, the placement of shear reinforcement and the moment on the shear interface. It found that shear-friction hypotheses for interface shear behaviour could be used in push-off specimens with reinforcing bar at angles to the shear plane and could be taken to calculate shear resistance.

Walraven (1987) proposed a new equation with a basic influencing parameter of concrete strength by studying the influence of sustaining loads and previous load cycles on shear stress of specimens with initial crack.

Bass et al. (1989) designed 33 push-off specimens to study the interface shear capacity between new concrete poured against an existing concrete surface. The influence of surface preparation, amount and depth of embedment of interface reinforcement, reinforcement detail in the new and existing concrete element, and both new and existing element strength on interface shear behaviour under repeated load was studied in detail.

Recently, Harries et al. (2012) investigated the complex nature of the shear-friction behaviour mechanism and then proposed a simple explanatory model and modified empirical design equation for calculating shear-friction capacity. Additionally, this study was the first to report the shear-friction behaviour including HS shear reinforcing bar with specified yield strength of $690 \mathrm{MPa}$.

Jiang et al. (2016a) studied the shear performance of grooved interfaces with shear transverse reinforcement between newly poured concrete and existing hardened concrete, with testing parameters of reinforcement ratio, concrete strength and groove geometry. After making a comparison with existing design provisions, it was found that the shear-friction theory might be used widely in many actual rehabilitation projects.

With the increasing use of HS concrete, an increasing number of relevant studes have been undertaken. Walraven (1981) and Walraven and Stroband (1994) carried out an experiment with concretes of compressive strength up to 9000 psi $(62.06 \mathrm{MPa})$, undertook an analysis of the aggregate interlock effect, and proposed a more accurate equation for shear transfer.

Mattock (2001) proposed a simple shear-friction design equation which would adapt for the horizontal interface shear behaviour between precast girders and cast-in-place slabs of
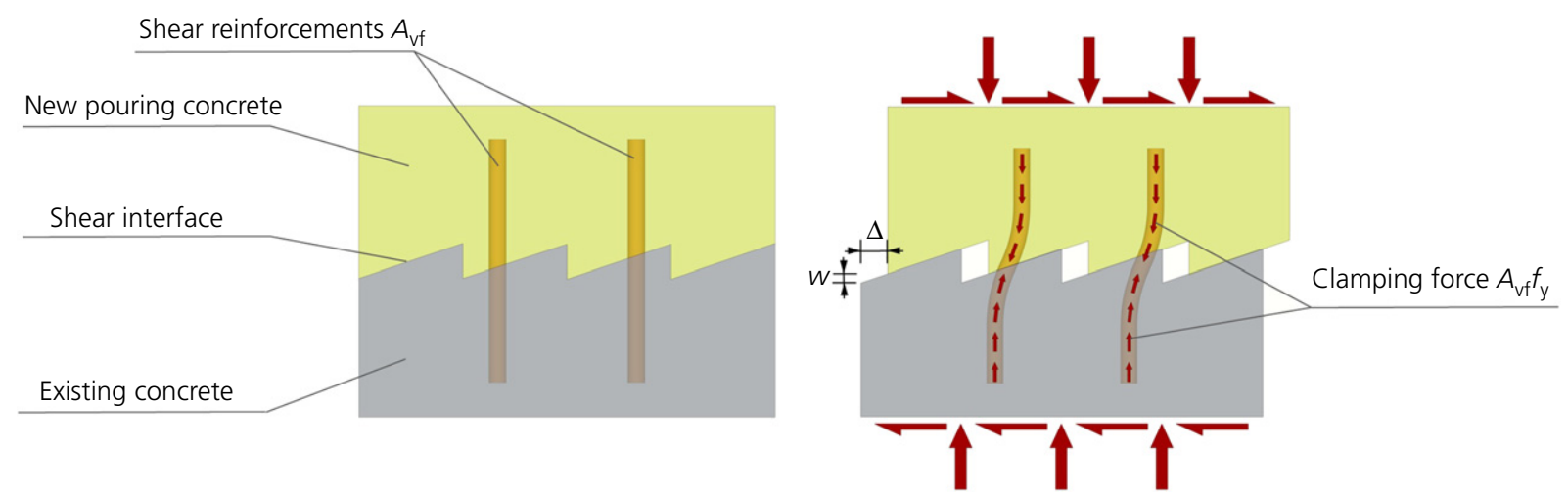

Figure 1. Shear-friction schematic proposed by Birkeland and Birkeland (1966) (redrawn) 
composite beams and accurately predict the shear transfer strength of all concretes.

Kahn and Mitchell (2002) performed 50 push-off tests of concrete having compressive strengths between $6800 \mathrm{psi}$ (46.89 MPa) and $17900 \mathrm{psi}(123 \mathrm{MPa})$ and transverse reinforcing ratios between $0 \cdot 37 \%$ and $1 \cdot 47 \%$. It was found that both the equation and limitation of the current ACI (ACI, 2014) shear-friction concept were not adapted for the specimens in this study, and a more accurate equation was proposed to predict the shear capacity of HS concrete specimens with coldjoint or uncracked interfaces.

Kuchma and Nagle (2007) conducted 18 push-off tests and 20 beam shear tests with HS concrete and different transverse reinforcement ratios to extend AASHTO LRFD 2015 (AASHTO, 2015) specifications to HS concrete of about $70 \mathrm{MPa}$. Test results also indicated that the theoretical values calculated by the AASHTO design provision (AASHTO, 2015) underestimate the experimentally measured capacity.

Similarly, LW concrete is often considered for use in precast concrete construction to reduce member weight and transportation costs and enhance fire resistance; so several studies on the interface shear behaviour of LW concrete have been done. Mattock et al. (1976) studied the influence of aggregate type, concrete strength, the amount of shear reinforcement, and precracking of an interface on LW concrete horizontal shear capacity. It was found that the shear transfer strength of LW concrete specimens was less than that of normal-weight $(\mathrm{NW})$ concrete specimens with the same compressive strength. The value of friction coefficients in the ACI (ACI, 2014) code have been multiplied by a factor to use in the design of connections between different types of LW concrete.

Based on 16 composite beam tests, Loov and Patnaik (1994) proposed an applicable equation which combined the influence of concrete strength and clamping stress and was applicable for both LW and semi-LW concrete. The tests also showed that stirrups were typically unstressed and ineffective until horizontal shear stresses exceed 1.5-2.0 MPa.

Shaw and Sneed (2014) and Sneed et al. (2016) investigated the applicability of the shear-friction concept for the shear interface behaviour of LW concrete cast at different times, with the variables of LW aggregate material, concrete unit weight, compressive strength, shear interface preparation, reinforcement ratio and crack interface condition.

Jiang et al. (2016b) studied the shear-friction behaviour of rough interfaces with shear transverse reinforcement between precast HS concrete girders and LW concrete cast-in-place slabs, with testing variables of LW coarse aggregate size, slab concrete type and shear reinforcement ratio. Results have found that current design codes are unsuitable for calculating the interface capacity between different types of concrete. Some of the conclusions were even inconsistent with existing theory; this highlights the importance of studying the smooth interface shear behaviour between HS and LW concrete. This paper presents the ongoing research work, which forms part of the same project as the former investigation (Jiang et al., 2016b). On the other hand, although the interfaces tested are relatively smooth in both cases, slight changes can also be found in this new test series.

Actually, the smooth interface condition may occur in actual civil engineering. For example, when using the maximum size of coarse aggregate (with a maximum size greater than $10 \mathrm{~mm}$ ) is inconvenient, the construction joint will then become a 'smooth interface' with the coarse aggregate protruding with an amplitude of less than $3 \mathrm{~mm}$. On the other hand, Shaw and Sneed (2014) have found that, after monolithic construction cracks, the shear capacity of cracking interfaces was similar to a cold-joint smooth interface condition. This disadvantageous situation could not be neglected because of the serious potential consequences. Thus, it is important to investigate this possible condition. Particularly, the interface condition in this study represented a lower-bound condition of the smooth interface case.

\section{Research significance}

This paper presents the results from ongoing research (Jiang et al., 2016b) into the direct shear transfer across an interface between HS and LW concretes. In this study, smooth interface specimens were investigated with variables of different LW concrete strengths and different shear reinforcement ratios. The applicability of several existing equations was examined. A modified equation which can accurately predict the ultimate shear stress and residual shear stress was then presented. The study reported here was directed towards developing shear-friction design recommendations for use in the design of connections for precast HS concrete girders and LW concrete slabs.

\section{Experimental programme}

\section{Variables}

Eighteen push-off specimens were tested in this study to investigate the shear behaviour of smooth interfaces between HS concrete and LW concrete. The aim of the study was to extend previous research (Jiang et al., 2016b) and fill in gaps in the literature on composite structures with smooth cold-joint condition. Table 1 lists the series designation and test matrix, in which two specimens ( $a$ and $b$ ) were tested for each series. As mentioned previously, a large number of parameters have an influence on interface shear performance. This research does not attempt to address them all. Two major test variables were investigated in this research, including LW slab concrete strength $f_{\mathrm{c}}^{\prime}$ and clamping stress $\rho f_{\mathrm{y}}$. For the first variable, specimens were tested with target cylinder compressive strengths of 30, 40 and $50 \mathrm{MPa}$ for slab concrete. To study the effect of 
Table 1. Series designation and test matrix

\begin{tabular}{|c|c|c|c|c|c|c|}
\hline $\begin{array}{l}\text { Series } \\
\text { designation }\end{array}$ & $\begin{array}{l}\text { Target girder } \\
\text { concrete } \\
\text { strength: } \mathrm{MPa}\end{array}$ & $\begin{array}{c}\text { Target slab } \\
\text { concrete } \\
\text { strength: } \mathrm{MPa}\end{array}$ & $\begin{array}{c}\text { Reinforcement } \\
\text { parameter }\end{array}$ & $\begin{array}{l}\text { Reinforcement } \\
\text { ratio, } \rho\end{array}$ & $\begin{array}{c}\text { Yield strength, } \\
f_{\mathrm{y}}: \mathrm{MPa}\end{array}$ & $\begin{array}{c}\text { Clamping } \\
\text { stress, } \rho f_{\mathrm{y}}: \mathrm{MPa}\end{array}$ \\
\hline S-C65L30-6D8-B & 65 & 30 & $6 \Phi 8$ & 0.008 & $285 \cdot 13$ & $2 \cdot 28$ \\
\hline S-C65L30-6D10-B & 65 & 30 & $6 \Phi 10$ & 0.012 & $411 \cdot 88$ & 4.94 \\
\hline S-C65L30-6D12-B & 65 & 30 & $6 \Phi 12$ & 0.018 & 418.98 & $7 \cdot 54$ \\
\hline S-C65L40-6D8-B & 65 & 40 & $6 \Phi 8$ & 0.008 & $285 \cdot 13$ & $2 \cdot 28$ \\
\hline S-C65L40-6D10-B & 65 & 40 & $6 \Phi 10$ & 0.012 & $411 \cdot 88$ & 4.94 \\
\hline S-C65L40-6D12-B & 65 & 40 & $6 \Phi 12$ & 0.018 & 418.98 & $7 \cdot 54$ \\
\hline S-C65L50-6D8-B & 65 & 50 & $6 \Phi 8$ & 0.008 & $285 \cdot 13$ & $2 \cdot 28$ \\
\hline S-C65L50-6D10-B & 65 & 50 & $6 \Phi 10$ & 0.012 & $411 \cdot 88$ & 4.94 \\
\hline S-C65L50-6D12-B & 65 & 50 & $6 \Phi 12$ & 0.018 & 418.98 & $7 \cdot 54$ \\
\hline
\end{tabular}

Note: Girder concrete is HS NW concrete; slab concrete is sand-LW concrete

variations in clamping stress, three types of stirrup were considered. Three two-leg stirrups were used in each specimen. Reinforcing bar diameters were either 8,10 or $12 \mathrm{~mm}$, which resulted in design clamping stresses of $2.28,4.94$ or $7.54 \mathrm{MPa}$, respectively.

\section{Concrete properties}

Four different concrete mixes were adopted in this study, including one for HS concrete and three for LW concrete. The same type of Pearl River sand was used as fine aggregate in all mixtures. Crushed granitic coarse aggregate, provided in a gradation of $16 \mathrm{~mm} \times 2.36 \mathrm{~mm}$, was used for constructing HS concrete, while the expanded shale coarse aggregate gradation used in the production of sand-LW concrete was $19 \mathrm{~mm} \times 2.36 \mathrm{~mm}$ sieve. Portland cement was used to achieve a target concrete compressive strength of $65 \mathrm{MPa}$ for the girder side and 30, 40 and $50 \mathrm{MPa}$ for the slab side, with water/cement ratios ranging from $0 \cdot 35$ to $0 \cdot 63$. Details of each concrete mixture are summarised in Table 2 . The density of concrete reflected the actual unit weights measured on the fresh concrete according to the procedure outlined in ASTM C138 (ASTM, 2017). Other properties of hardened concrete, including cylinder concrete compressive strength $f_{\mathrm{c}}^{\prime}$ (ASTM, 2015), splitting tensile strength $f_{\mathrm{t}}$ (ASTM, 2011), modulus of elasticity $E_{\mathrm{c}}$ (ASTM, 2014) and Poisson's ratio (ASTM, 2014), were tested on the same day as the corresponding pushoff specimens. All specimens had the same girder concrete compressive strength of $66 \cdot 15 \mathrm{MPa}$, which would minimise the differences of the web concrete compressive strength at test day as far as possible. It can also be noted that both the tensile strength and modulus of elasticity for higher-strength LW concrete are slightly larger than those of the lower-strength one, but much smaller than those of HS NW concrete.

\section{Specimen description}

Details of test specimens and reinforcements are shown in Figure 2, which have been commonly used in previous studies (Hofbeck and Ibrahim, 1969; Jiang et al., 2016b; Kahn and Mitchell, 2002; Mattock, 1976; Mattock and Hawkins, 1972).
The shear interface was $250 \mathrm{~mm}$ long and $150 \mathrm{~mm}$ wide with an area $A_{\mathrm{c}}$ of $37500 \mathrm{~mm}^{2}$. Only shear force was transferred across the interface when loading, as indicated by the arrow shown in the figure. Shear reinforcements consisted of three welded closed stirrups normal to the shear interface to ensure good anchorage of reinforcing bars on each side of the specimens. All types of reinforcement used in this study were from the same shipment, and the details of the mechanical properties of reinforcing bars used in this test are summarised in Table 3. The measured yield strength $f_{\mathrm{y}}$ of the stirrups with diameter of $8 \mathrm{~mm}$ was $285 \cdot 13 \mathrm{MPa}$, while for the stirrups with diameter of 10 and $12 \mathrm{~mm}$ it was 411.88 and 418.98 MPa, respectively.

Table 4 lists the identifications of each specimen. Two replicate specimens were tested with each combination of test variables. The specimen designation indicates the interface condition ( $\mathrm{S}=$ smooth shear interface); the target compressive strength of concrete at test day in units of MPa $(\mathrm{C} 65=65 \mathrm{MPa}$ for HS girder concrete; L30 $=30 \mathrm{MPa}$ for $\mathrm{LW}$ deck concrete; $\mathrm{L} 40=40 \mathrm{MPa}$ for $\mathrm{LW}$ slab concrete; $\mathrm{L} 50=50 \mathrm{MPa}$ for $\mathrm{LW}$ deck concrete); the quantities of reinforcement crossing the shear interface $(6 \mathrm{D} 8,6 \mathrm{D} 10,6 \mathrm{D} 12=$ six reinforcing bars with diameters of 8,10 and $12 \mathrm{~mm}$, respectively); concrete type $(\mathrm{B}=\mathrm{LW}$ concrete with coarse aggregate granular of 5-20 mm); and specimen number of duplicate specimens (a or b). Table 4 also summarises results for each test specimen. Clamping stress $\rho f_{\mathrm{y}}$ is the clamping shear force $A_{\mathrm{v} f} f_{\mathrm{y}}$ divided by the area of the shear plane $A_{\mathrm{c}} ; f_{\mathrm{c}}^{\prime}$ is the cylinder concrete compressive strength for the weaker half of specimens at test day; $v_{\mathrm{ec}}$ is the experimental cracking shear stress at the first crack appearance on the shear plane; $v_{\mathrm{eu}}$ is the experimental ultimate (peak) shear stress measured during testing; and $v_{\mathrm{er}}$ is the experimental residual shear stress corresponding to a slip of $3.81 \mathrm{~mm}$ in the test as suggested by Shaw and Sneed (2014). Table 4 also records the slip and dilation of the shear plane measured at the peak shear force. Values of the slip are the average of the direct-current linear variable displacement transducer (DC-LVDT) measurements from two sides of the shear plane. 


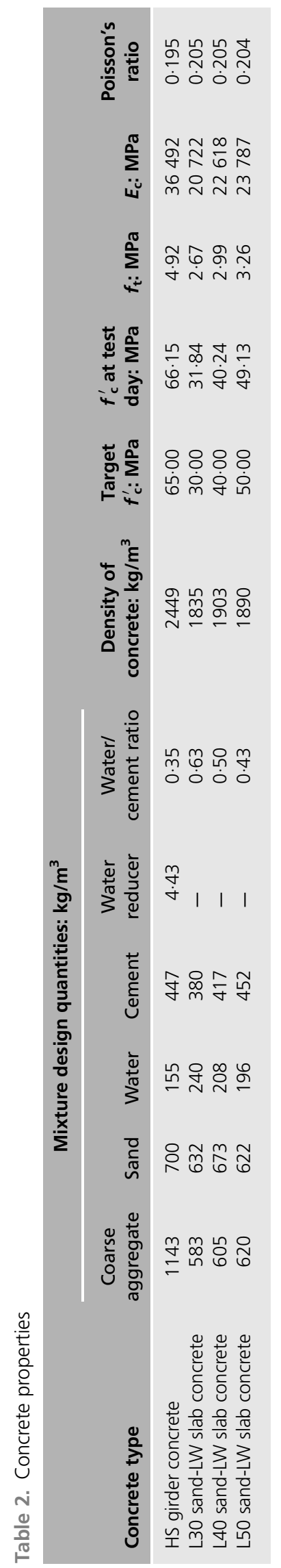

\section{Specimen fabrication}

The test specimens were constructed to investigate the interface between HS concrete girders and cast-in-place LW concrete slabs with custom-built formwork. All the specimens were cast in two stages. The girder portion was first fabricated with stirrups projecting from it (Figure 3(a)). When the girder concrete was still wet, the interface was trowelled smooth, to an average surface amplitude of less than $0.5 \mathrm{~mm}$ (Figure 3(b)). Specimens were cured in a moist condition after removing the formwork. The slab part of the specimens was fabricated after the girder part had been cured for 2 weeks. Prior to pouring the slab side of concrete, the interface was cleaned with fresh water and compressed air. Figure 3(c) shows the formwork for the slab portion before casting. After removing the mould, the concrete control cylinders and the corresponding test specimens were cured under similar conditions until the date of testing (Figure 3(d)).

\section{Experimental setup and instrumentation}

The specimens were tested $28 \mathrm{~d}$ after casting the LW slab concrete. Figure 4 shows a schematic of the test setup and instrumentation in detail. All specimens were loaded in compression concentric to the shear interface with a spherical seated platen to allow rotational freedom. Tests were conducted by a displacement-controlled actuator with a hand pump at a rate of approximately $0 \cdot 1 \mathrm{~mm} / \mathrm{min}$. Loading was paused at increments of $0.05 \mathrm{~mm}$ to observe the development of cracks and mark cracks and to take photographs. The specimens were tested until the displacement of the shear plane reached $4.0 \mathrm{~mm}$. Two DC-LVDTs were installed, one on each side of the interface, to monitor slip of the shear plane. One additional DC-LVDT was installed on the specimen to monitor dilation of the shear interface. As shown in Figure 2, in total eight strain gauges were located on the middle closed stirrup to study the behaviour of the reinforcement across the shear plane. In order to protect the strain gauges, the strain gauges near the cold joint were located $1 \mathrm{~cm}$ from the interface.

\section{Results and discussion}

Table 4 summarises the test results of this study, including slab concrete compressive strength at test day, cracking shear stresses, ultimate shear stresses, residual shear stresses, slippages and dilations at ultimate shear stresses.

\section{Observed behaviour}

The typical cracking pattern is shown in Figure 5, which is representative of most specimens. Very few splitting cracks were observed on both sides of specimens before cracking was observed adjacent to the interface (Figure 5(a)). With increased loading, initial cracks developed, new splitting cracks around the specimens appeared, and vertical cracks were observed adjacent to the interface (Figure 5(b)). When ultimate capacity 


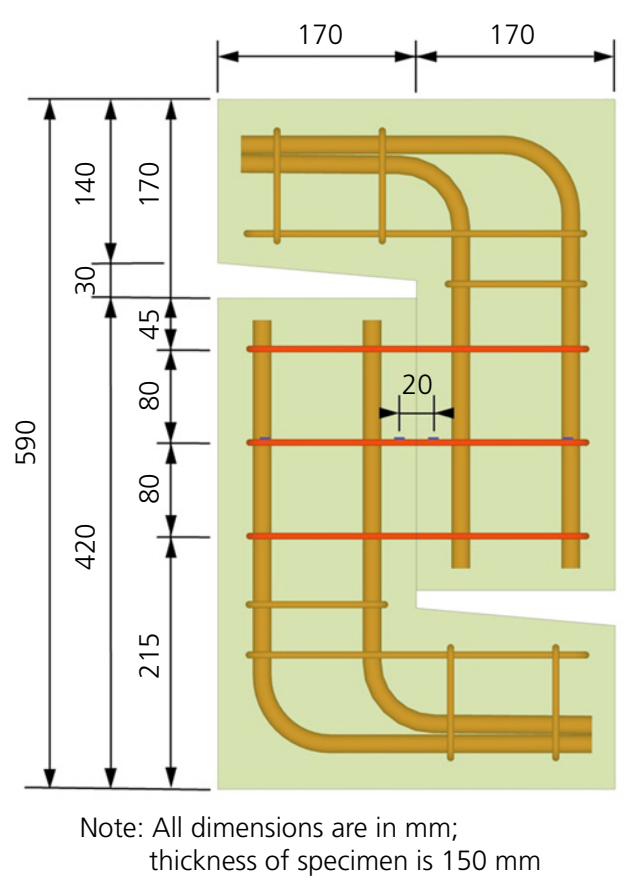

(a)

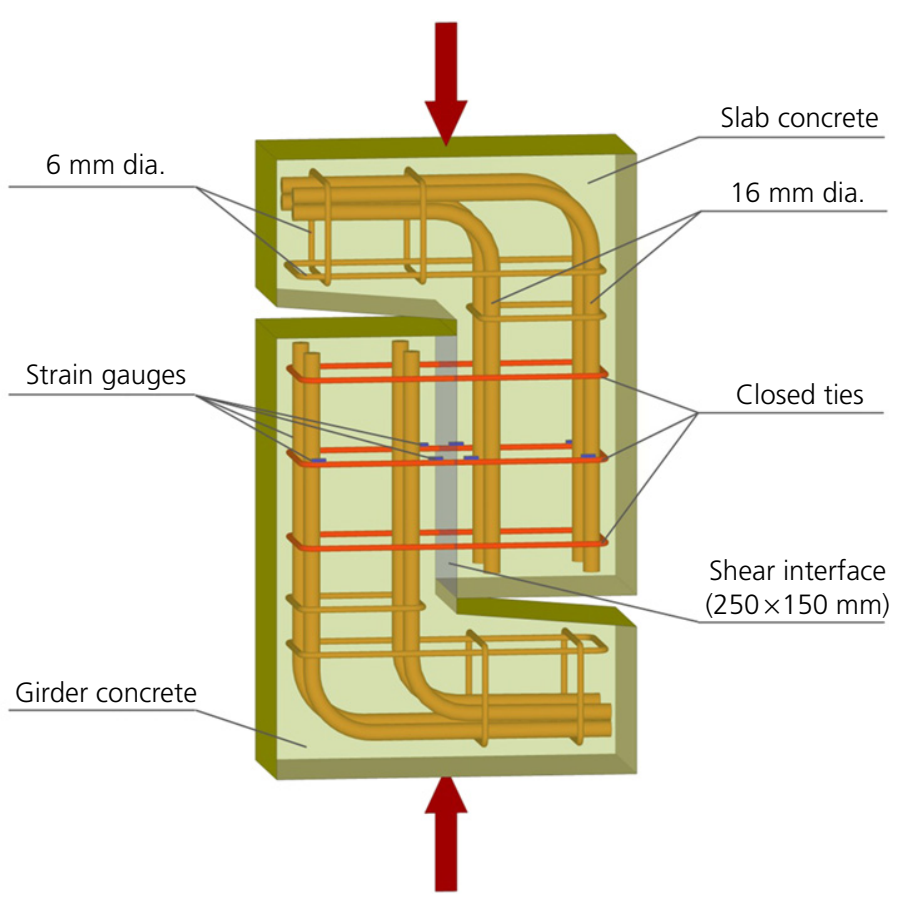

(b)

Figure 2. Details of specimen dimensions and reinforcement: (a) dimensions of specimen; (b) three-dimensional view of specimens

Table 3. Reinforcement properties

\begin{tabular}{|lccc|}
\hline Type & $\begin{array}{c}\text { Yield } \\
\text { strength: } \\
\mathbf{M P a}\end{array}$ & $\begin{array}{c}\text { Ultimate } \\
\text { tensile } \\
\text { strength: } \mathbf{M P a}\end{array}$ & $\begin{array}{c}\text { Modulus } \\
\text { of elasticity: } \\
\mathbf{M P a}\end{array}$ \\
\hline $8 \mathrm{~mm}$ dia. bar & 285.13 & 429.41 & $1.97 \times 10^{5}$ \\
$10 \mathrm{~mm}$ dia. bar & 411.88 & 559.07 & $2.03 \times 10^{5}$ \\
$12 \mathrm{~mm}$ dia. bar & 418.98 & 535.87 & $2.05 \times 10^{5}$ \\
\hline
\end{tabular}

was reached, the interface failed in shear due to the surface cracks lengthening and linking with others (Figure 5(c)).

Failure modes for specimens with different shear reinforcement ratios are shown in Figure 6, which are highly similar across different specimens. Specimens with a higher reinforcement ratio exhibited more splitting cracks and greater slippage or dilation for the shear interface at ultimate load. In addition, a small amount of compression spalling of the concrete was observed adjacent to the shear interface crack for several specimens. Generally, most specimens exhibited several splitting cracks, and the main failure modes of these specimens were shear along the shear interface. However, specimens S-C65L30-6D10-Ba and S-C65L40-6D12-Bb failed in concrete splitting adjacent to the interface (Figure 7), causing the lower shear capacity of the specimens. These premature failures were mainly due to the tensile force caused by the dowel action of the interface reinforcement. So as to be able to come to some rational conclusion, the results of specimens S-C65L30-6D10-Ba and S-C65L40-6D12-Bb were not adopted.

\section{Applied shear stress-slip relations}

Figure 8 shows applied shear stress-slip relations for specimens with clamping stress of $2.28,4.94$ and $7.54 \mathrm{MPa}$, respectively. Curves exhibited similar initial stiffness for specimens with the same clamping stress. From the beginning of loading, the shear capacity of the specimen increased with the increase in interface shear slippage. After achieving the peak value of shear stress, maximum shear resistance was not maintained as the slip increased but decreased to a nearly constant residual capacity (i. e. the residual shear stress). In general, the ultimate shear stress, residual shear stress and slip at ultimate shear stress were higher for more heavily reinforced specimens than for those of more lightly reinforced specimens. It can also be found that LW concrete strength has only a slight influence on interface shear capacity. Specimens with higher reinforcement ratios behaved in a more brittle fashion than the corresponding specimens with lower reinforcement ratio; that is, the shear resistance after ultimate capacity decreased more rapidly with increasing slip. From another perspective, deformation behaviour was found to become more brittle as the compressive strength of the LW slab concrete increased.

\section{Shear stress}

\section{Effect of LW concrete strength}

Three types of interface shear stress were plotted versus LW concrete strength, with different shear clamping stress (Figure 9). The results show that LW slab concrete strengths have a very slight influence on the cracking shear stress of the 
Magazine of Concrete Research Volume 72 Issue 2
Shear-friction behaviour on smooth interface between high-strength and

lightweight concrete

Fang, Jiang, Liu, Feng and Li

Table 4. Summary of test results

\begin{tabular}{|c|c|c|c|c|c|c|c|c|c|c|c|}
\hline Number & $\begin{array}{l}\text { Specimen } \\
\text { identification }\end{array}$ & $\begin{array}{l}\text { Clamping } \\
\text { stress, } \\
\rho f_{\mathrm{y}}: \mathrm{MPa}\end{array}$ & $\begin{array}{c}f_{\mathrm{c}}^{\prime} \text { at test } \\
\text { day: } \\
\mathrm{MPa}\end{array}$ & $\begin{array}{l}V_{\mathrm{ec}}: \\
\mathrm{MPa}\end{array}$ & $\begin{array}{c}\text { Average } \\
V_{\text {ec: }} \\
\text { MPa }\end{array}$ & $\begin{array}{l}V_{\text {eu }}: \\
\mathrm{MPa}\end{array}$ & $\begin{array}{c}\text { Average } \\
\boldsymbol{v}_{\text {eu: }} \\
\mathrm{MPa}\end{array}$ & $\begin{array}{c}\text { Slippage } \\
\text { at } v_{\text {eu }}: \\
\text { mm }\end{array}$ & $\begin{array}{c}\text { Dilation } \\
\text { at } v_{\text {eu: }} \\
\text { mm }\end{array}$ & $\begin{array}{l}v_{\text {er: }} \\
\mathrm{MPa}\end{array}$ & $\begin{array}{c}\text { Average } \\
V_{\mathrm{er}}: \\
\mathrm{MPa}\end{array}$ \\
\hline 1 & S-C65L30-6D8-Ba & $2 \cdot 28$ & $31 \cdot 84$ & 3.45 & $2 \cdot 72$ & $3 \cdot 55$ & $3 \cdot 37$ & 0.59 & $0 \cdot 13$ & $3 \cdot 46$ & $3 \cdot 29$ \\
\hline 2 & S-C65L30-6D8-Bb & $2 \cdot 28$ & $31 \cdot 84$ & 1.99 & & $3 \cdot 19$ & & 0.46 & $0 \cdot 12$ & $3 \cdot 11$ & \\
\hline 3 & S-C65L30-6D10-Ba ${ }^{a}$ & 4.94 & $31 \cdot 84$ & 2.91 & - & $3 \cdot 75$ & - & 0.90 & $0 \cdot 14$ & $3 \cdot 13$ & - \\
\hline 4 & $\mathrm{~S}-\mathrm{C} 65 \mathrm{~L} 30-6 \mathrm{D} 10-\mathrm{Bb}$ & 4.94 & $31 \cdot 84$ & $2 \cdot 68$ & $2 \cdot 68$ & $5 \cdot 57$ & $5 \cdot 57$ & 0.82 & $0 \cdot 20$ & $4 \cdot 79$ & $4 \cdot 79$ \\
\hline 5 & S-C65L30-6D12-Ba & $7 \cdot 54$ & $31 \cdot 84$ & $3 \cdot 21$ & $3 \cdot 31$ & $6 \cdot 83$ & $7 \cdot 03$ & 0.78 & $0 \cdot 20$ & $5 \cdot 77$ & $5 \cdot 76$ \\
\hline 6 & $\mathrm{~S}-\mathrm{C} 65 \mathrm{~L} 30-6 \mathrm{D} 12-\mathrm{Bb}$ & $7 \cdot 54$ & $31 \cdot 84$ & 3.41 & & $7 \cdot 23$ & & 0.76 & 0.22 & $5 \cdot 75$ & \\
\hline 7 & S-C65L40-6D8-Ba & $2 \cdot 28$ & $40 \cdot 24$ & $2 \cdot 62$ & $2 \cdot 52$ & $3 \cdot 17$ & $3 \cdot 16$ & $0 \cdot 31$ & $0 \cdot 12$ & $2 \cdot 60$ & $2 \cdot 64$ \\
\hline 8 & S-C65L40-6D8-Bb & $2 \cdot 28$ & $40 \cdot 24$ & $2 \cdot 42$ & & $3 \cdot 15$ & & 0.59 & $0 \cdot 20$ & $2 \cdot 68$ & \\
\hline 9 & S-C65L40-6D10-Ba & 4.94 & $40 \cdot 24$ & $3 \cdot 88$ & $3 \cdot 28$ & $5 \cdot 53$ & $5 \cdot 16$ & 0.58 & $0 \cdot 10$ & $4 \cdot 17$ & $4 \cdot 17$ \\
\hline 10 & S-C65L40-6D10-Bb & 4.94 & $40 \cdot 24$ & $2 \cdot 68$ & & $4 \cdot 78$ & & 0.52 & 0.24 & $4 \cdot 18$ & \\
\hline 11 & S-C65L40-6D12-Ba & $7 \cdot 54$ & $40 \cdot 24$ & 3.02 & 3.02 & 8.40 & $8 \cdot 40$ & 1.04 & $0 \cdot 31$ & $6 \cdot 70$ & $6 \cdot 70$ \\
\hline 12 & $\mathrm{~S}-\mathrm{C} 65 \mathrm{~L} 40-6 \mathrm{D} 12-\mathrm{Bb}^{\mathrm{a}}$ & $7 \cdot 54$ & $40 \cdot 24$ & $3 \cdot 21$ & - & $6 \cdot 71$ & - & 0.72 & 0.25 & $4 \cdot 18$ & - \\
\hline 13 & S-C65L50-6D8-Ba & $2 \cdot 28$ & $49 \cdot 13$ & $3 \cdot 16$ & $3 \cdot 12$ & $3 \cdot 71$ & $4 \cdot 13$ & $0 \cdot 34$ & $0 \cdot 13$ & 3.05 & $3 \cdot 18$ \\
\hline 14 & S-C65L50-6D8-Bb & $2 \cdot 28$ & $49 \cdot 13$ & 3.09 & & $4 \cdot 56$ & & $0 \cdot 30$ & $0 \cdot 13$ & $3 \cdot 32$ & \\
\hline 15 & S-C65L50-6D10-Ba & 4.94 & $49 \cdot 13$ & 3.71 & $3 \cdot 34$ & 6.02 & 5.93 & 0.71 & 0.22 & $4 \cdot 27$ & 4.59 \\
\hline 16 & S-C65L50-6D10-Bb & 4.94 & $49 \cdot 13$ & 2.96 & & 5.83 & & 0.63 & $0 \cdot 19$ & 4.90 & \\
\hline 17 & S-C65L50-6D12-Ba & $7 \cdot 54$ & $49 \cdot 13$ & $4 \cdot 26$ & $3 \cdot 87$ & $7 \cdot 14$ & $7 \cdot 78$ & 0.85 & 0.29 & $5 \cdot 20$ & $5 \cdot 70$ \\
\hline 18 & $\mathrm{~S}-\mathrm{C} 65 \mathrm{~L} 50-6 \mathrm{D} 12-\mathrm{Bb}$ & $7 \cdot 54$ & $49 \cdot 13$ & 3.48 & & 8.41 & & 0.48 & 0.31 & $6 \cdot 20$ & \\
\hline
\end{tabular}

Interface did not fail

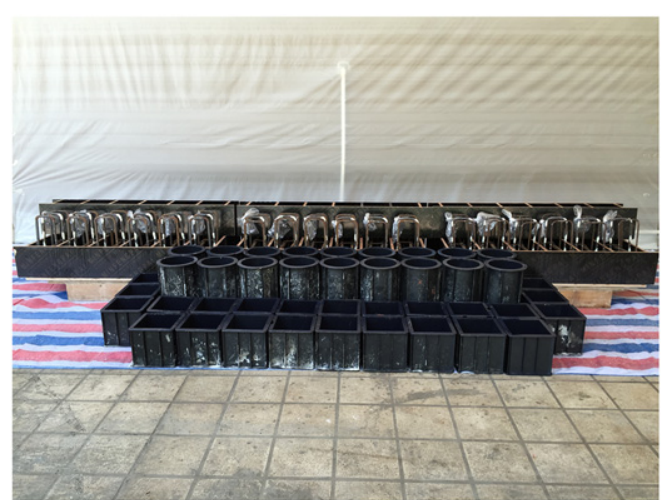

(a)

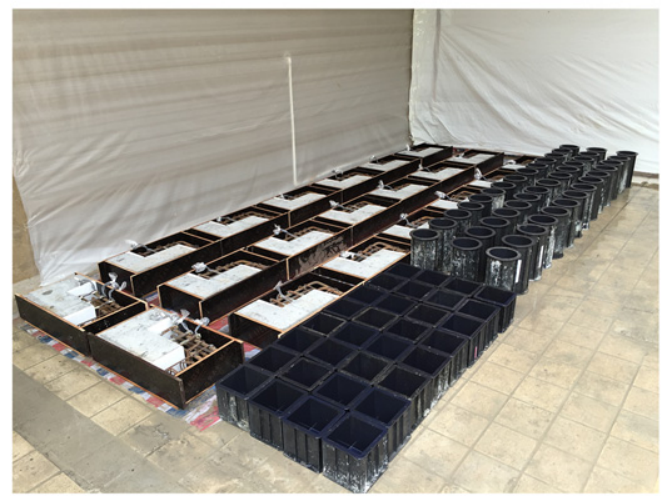

(c)

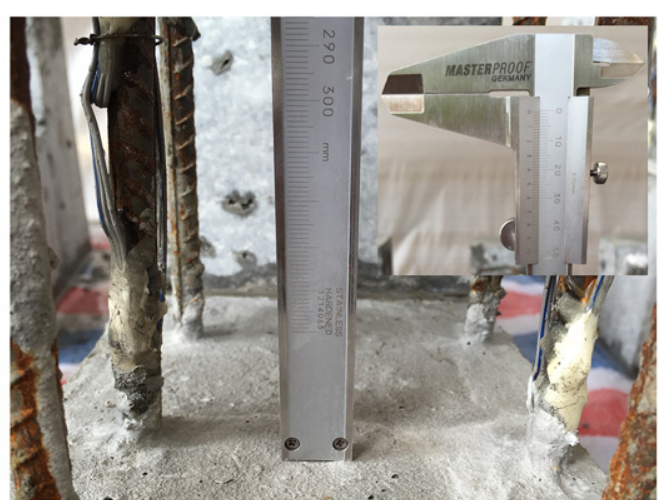

(b)

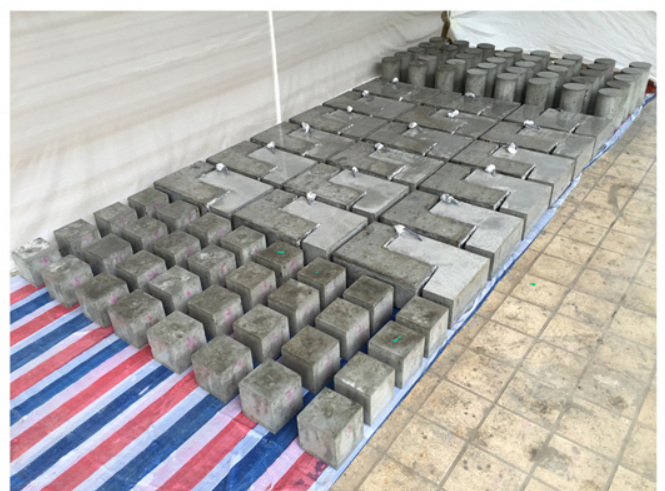

(d)

Figure 3. Testing specimen casting programme: (a) formwork for girder side; (b) preparation for shear interface; (c) formwork for slab side; (d) specimens before testing 
shear plane (Figure 9(a)). Specimens with a slab concrete strength of $49 \cdot 13 \mathrm{MPa}$ always undergo higher cracking stress than specimens with a slab concrete strength of $31.84 \mathrm{MPa}$ in the same series. This phenomenon may be associated with the stronger cracking resistance capacity (i.e. splitting tensile

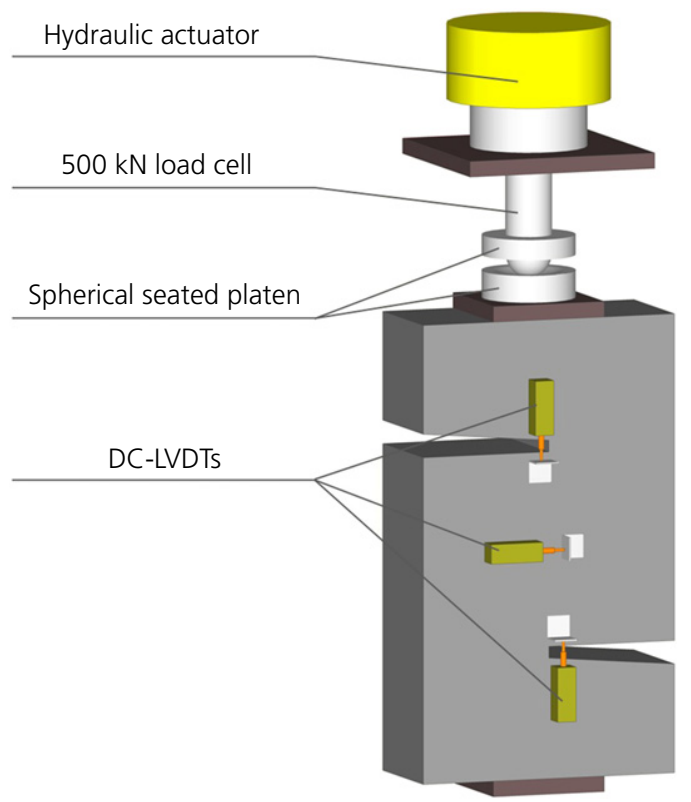

Figure 4. Schematic of test setup and instrumentation strength) of higher LW concrete strength as shown in Table 2. Trend lines in Figure 9(b) reveal that the ultimate shear stress of interfaces increased with the increase in LW concrete strength. An increase of LW concrete strength from 31.84 MPa to $49.13 \mathrm{MPa}$ resulted in an increase of ultimate shear stress by $22 \cdot 55 \%$ for specimens with a clamping stress of $2 \cdot 28 \mathrm{MPa}$. While for specimens with a clamping stress of 4.94 and $7.54 \mathrm{MPa}$, this increase in ultimate shear stress was 6.46 and $10.67 \%$, respectively. It is therefore recommended that the shear-friction equation should include the effect of LW concrete strength. In Figure 9(c), it can be found that specimens with the same reinforcing parameter have similar residual shear stress, irrespective of LW concrete stress. This result suggests that LW concrete strength did not play a significant role in the interface residual shear stress of specimens in this research.

\section{Effect of clamping stress}

Figure 10 plots three types of interface shear stress versus clamping stress, with a comparison between different LW concrete strengths. Similar to the effects of LW concrete strength on the cracking stress of the interface, the clamping stress had a slight effect on the cracking shear stress of the interface (Figure 10(a)). This may result from the higher clamping stress for specimens with a higher shear reinforcement ratio, which provides more frictional resistance. As shown in Figure 10(b), when the shear reinforcement parameter $\rho f_{\mathrm{y}}$ increased from $2 \cdot 28$ to $7 \cdot 54 \mathrm{MPa}$, the increase of the ultimate

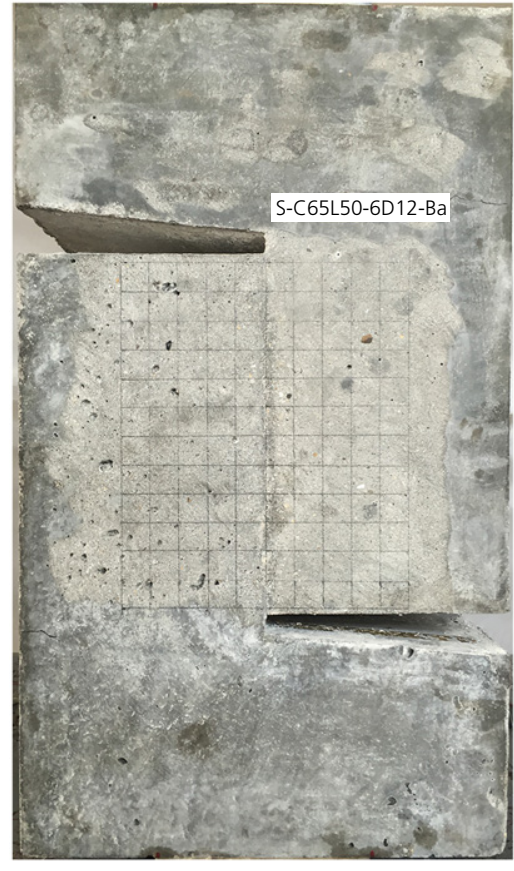

(a)

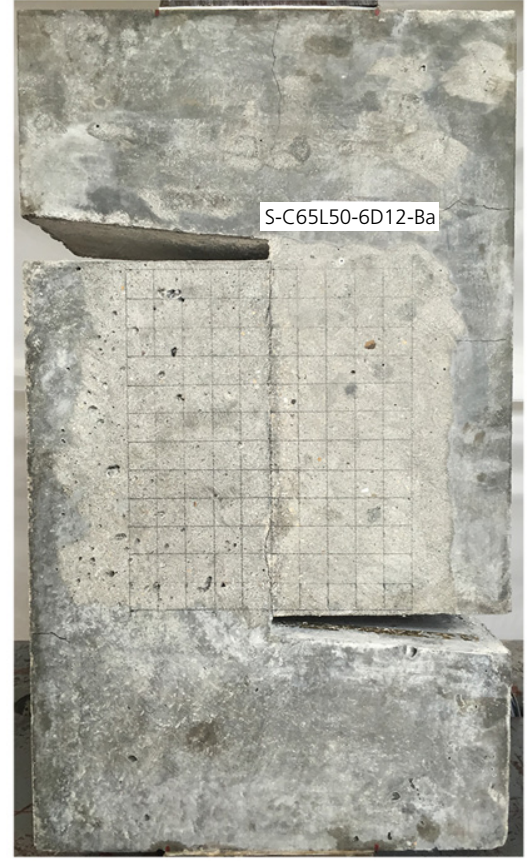

(b)

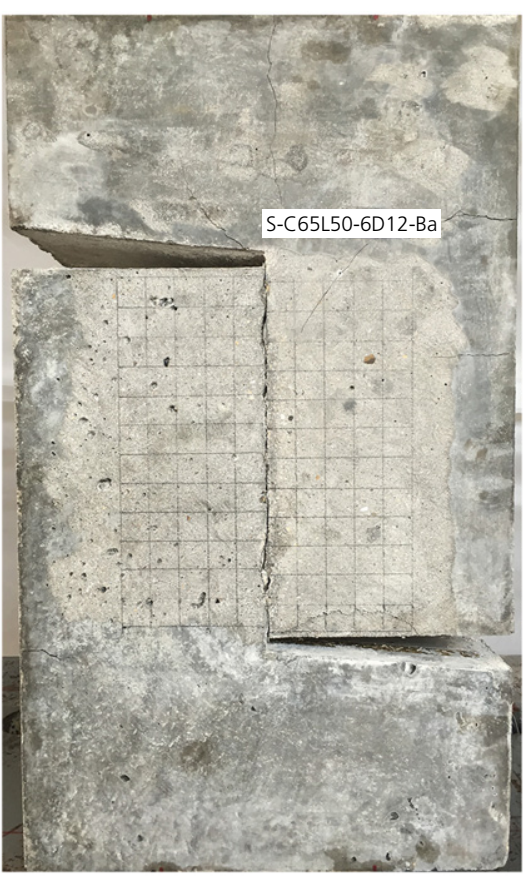

(c)

Figure 5. Typical cracking patterns of specimens: (a) crack initiation; (b) crack propagation; (c) failure mode 


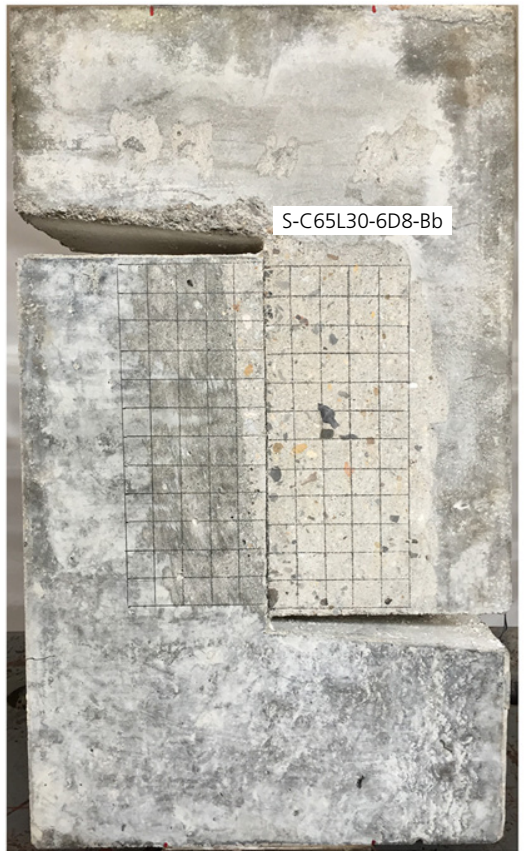

(a)

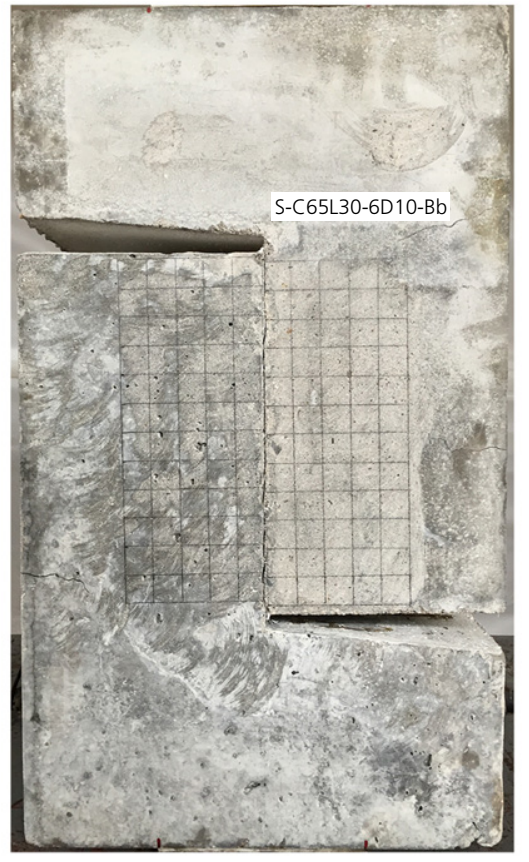

(b)

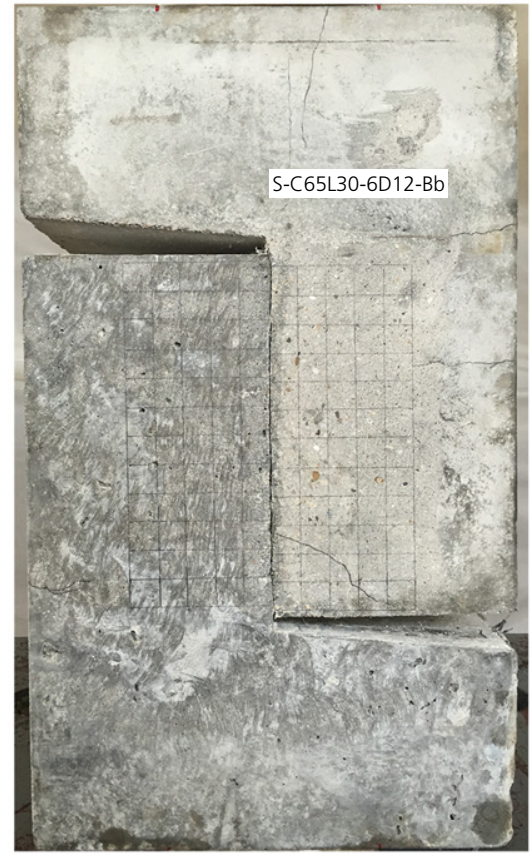

(c)

Figure 6. Failure modes for specimen with different clamping stress: (a) specimen S-C65L30-6D8-Bb; (b) specimen S-C65L30-6D10-Bb; (c) specimen S-C65L30-6D12-Bb

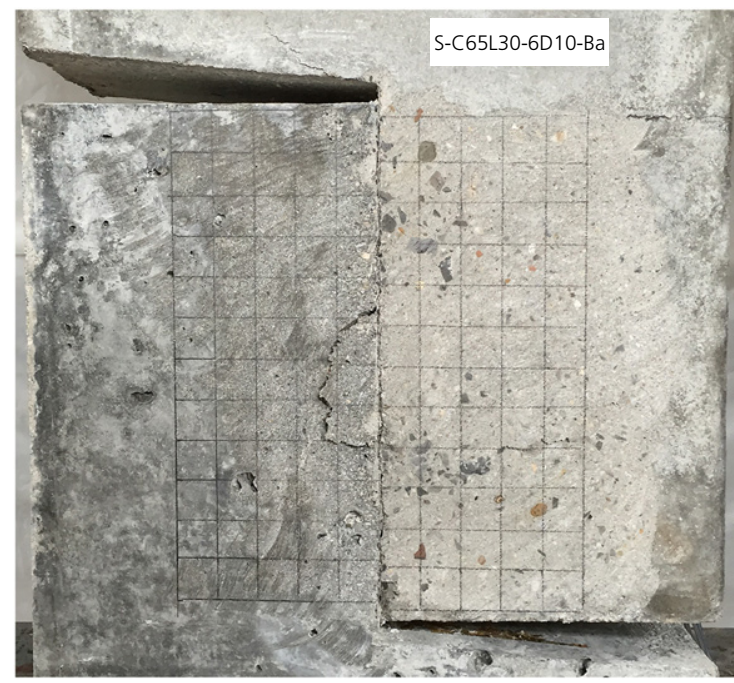

(a)

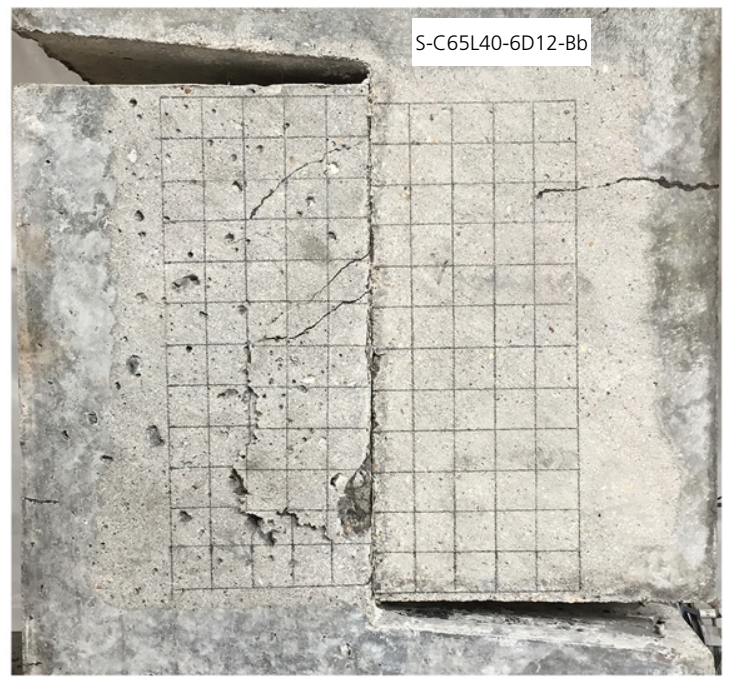

(b)

Figure 7. Typical splitting failure modes: (a) specimen S-C65L30-6D10-Ba; (b) specimen S-C65L40-6D12-Bb

shear stress for specimens with $31 \cdot 84,40 \cdot 24$, and $49 \cdot 13 \mathrm{MPa}$ were $108 \cdot 61,165 \cdot 82$ and $88 \cdot 38 \%$, respectively. Similarly, when the shear reinforcement parameter $\rho f_{\mathrm{y}}$ increased from $2 \cdot 28$ to $7.54 \mathrm{MPa}$, it can be seen in Figure 10(c) that the increase of ultimate shear stress for specimens with $31 \cdot 84,40 \cdot 24$ and $49 \cdot 13 \mathrm{MPa}$ were $75 \cdot 08,153 \cdot 79$ and $79 \cdot 25 \%$, respectively. Thus, clamping stress plays a significant role in ultimate shear stress and residual shear stress. Higher clamping stress may promote the capacity of the shear interface by restraining the widening of cracks in a direction perpendicular to the shear plane. When dropping to the residual capacity, it may provide a stronger clamping force and bond strength between LW concrete and shear reinforcement for higher clamping stress specimens. 


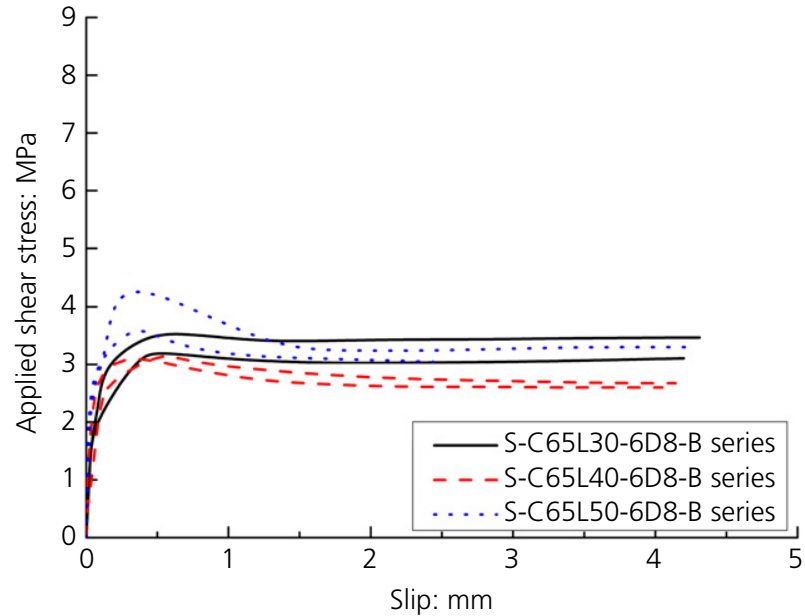

(a)

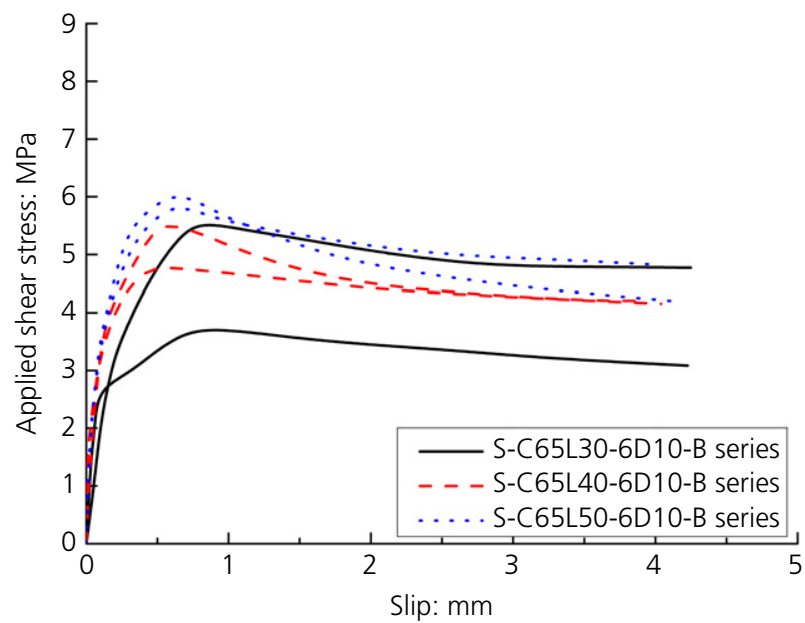

(b)

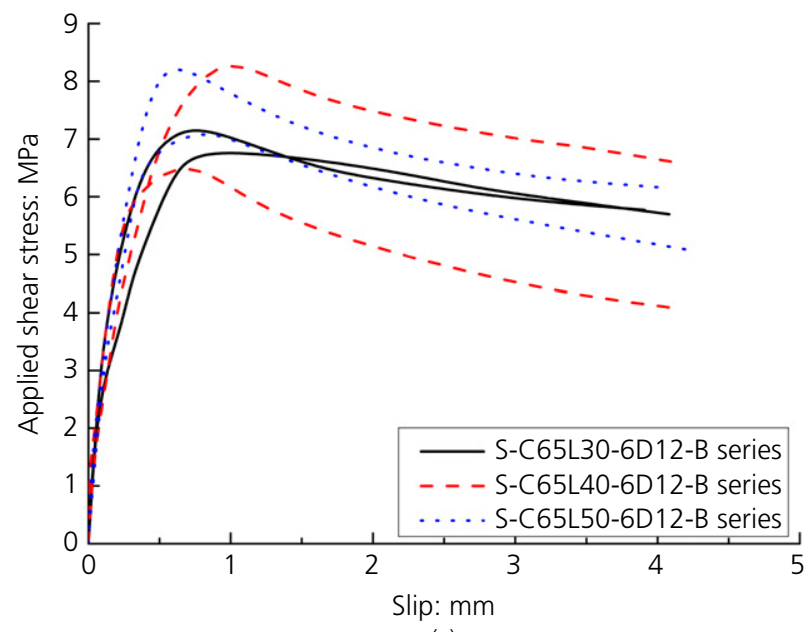

(c)

Figure 8. Applied shear stress-slip relations for test specimens: (a) specimens with clamping stress of $2.28 \mathrm{MPa}$; (b) specimens with clamping stress of $4.94 \mathrm{MPa}$; (c) specimens with clamping stress of $7.54 \mathrm{MPa}$

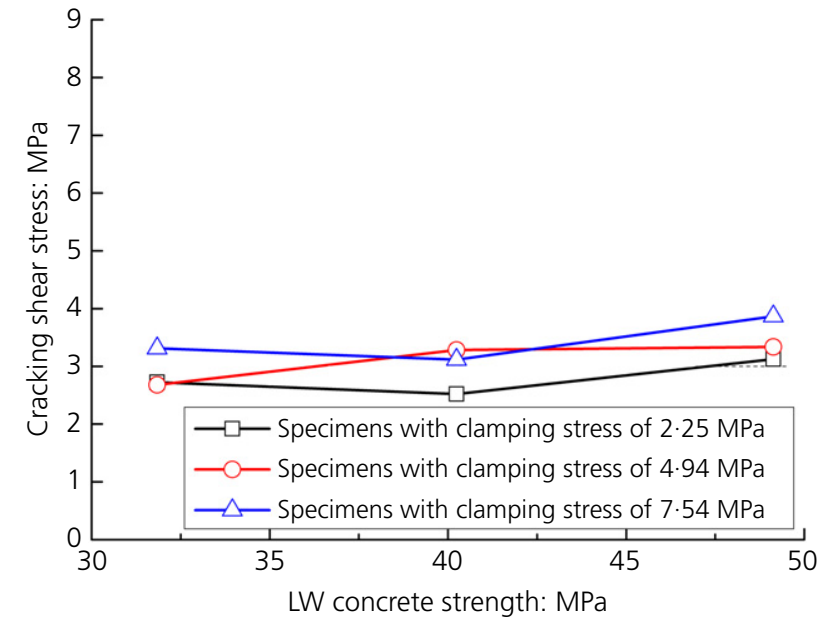

(a)

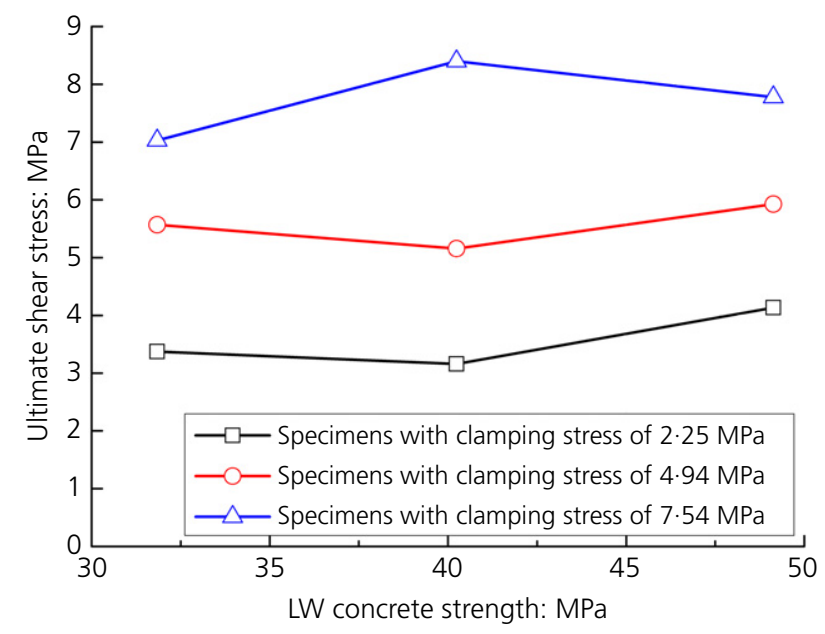

(b)

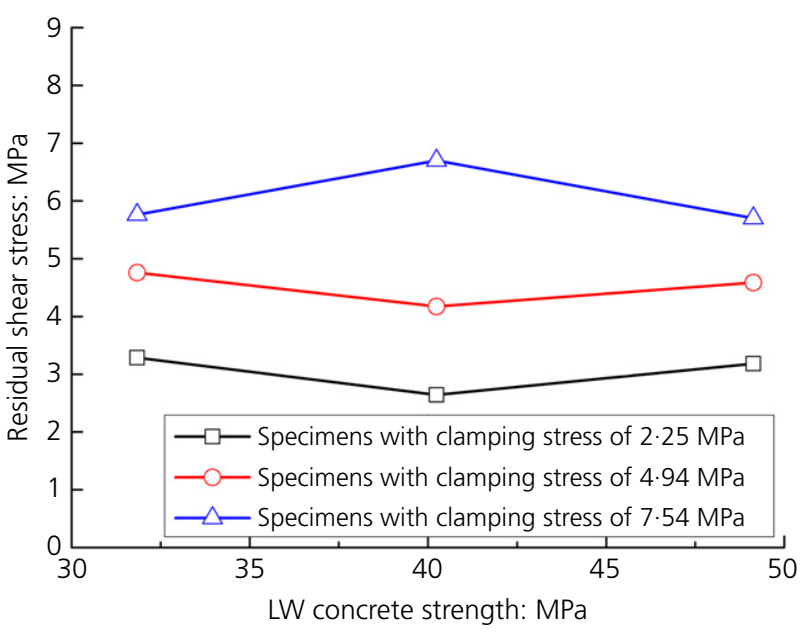

(c)

Figure 9. Effect of LW concrete strength on interface shear stress: (a) cracking shear stress; (b) ultimate shear stress; (c) residual shear stress 


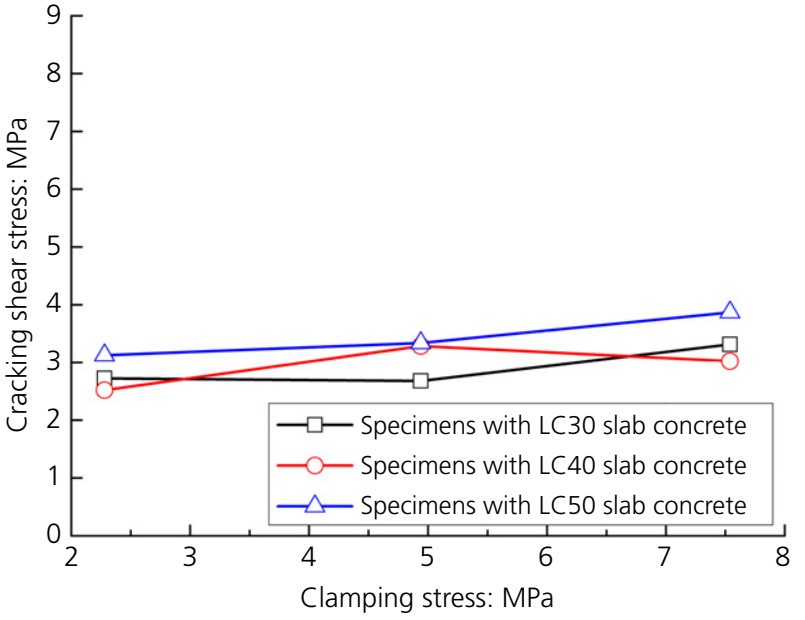

(a)

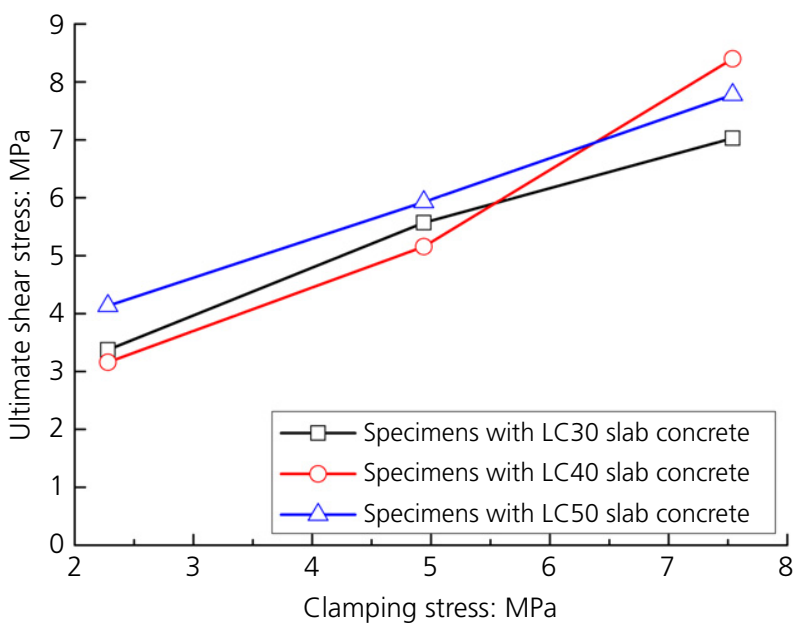

(b)

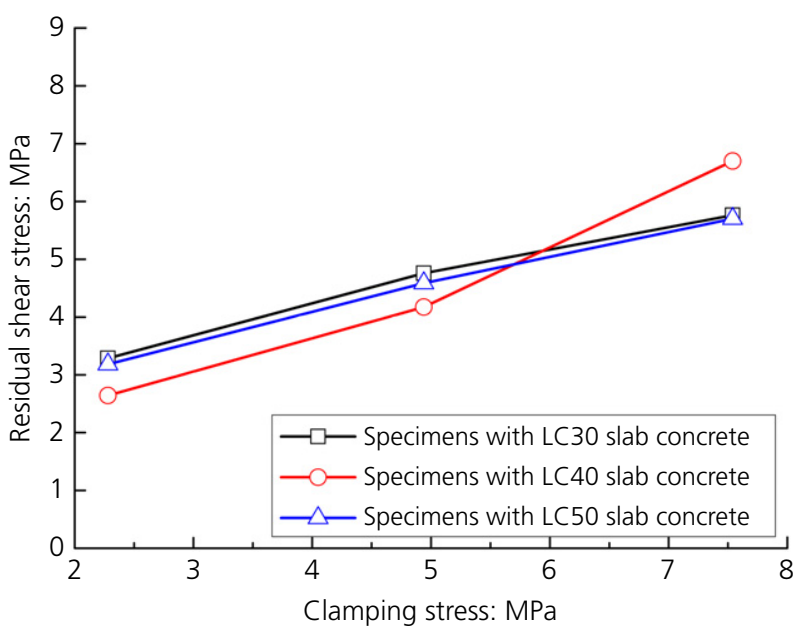

(c)

Figure 10. Effect of clamping stress on interface shear stress: (a) cracking shear stress; (b) ultimate shear stress; (c) residual shear stress

\section{Slippages and dilations at ultimate shear stress}

The interface vertical slippages increase with the increasing of shear strength, while the horizontal dilations increase with the increasing of shear strength after the cracking of the interface. Table 4 summarises the shear interface vertical slippages and horizontal dilations for all of the specimens at ultimate shear stress.

It can be found that the slippages at ultimate shear stress appear not to be affected by the strength of LW slab concrete, while the slips at peak capacity increased with the increasing of clamping stress, but stop increasing or even decrease at higher clamping stress. On the other hand, interface horizontal dilations at ultimate shear stress increased significantly with the increasing of clamping stress, irrespective of LW concrete strength. This may be associated with the higher clamping force for specimens with higher clamping stress.

\section{Development of shear-friction}

As mentioned previously, shear-friction strength of the shear plane consisted of interface cohesion and aggregate interlock action originating from the clamping force caused by shear reinforcement. Although the interfaces were trowelled smooth to achieve a surface with an amplitude of less than $0.5 \mathrm{~mm}$ (i.e. not absolutely smooth), the aggregate interlock interaction also exists. Fine aggregate protruded from the interface and the rougher failure surface will provide the aggregate interlock interaction. Indeed, the aggregate interlock interaction for the smooth interface condition is less than that for the rough interface condition. To illustrate this theory, the shear capacity of the interface was decomposed into its steel clamping force component and concrete shear component. Figure 11 shows the typical slip-strain curves at the location of stirrup adjacent to the interface. The typical components of shear-friction behaviour for specimens of S-C60L50-8D12-Ba are shown in Figure 12. These are similar to those of other specimens.

The four stirrups far away from the interface were not effective while the four stirrups near the interface recorded approximately similar steel strain. Figure 11 shows typical slip-strain curves at the location of stirrups adjacent to an interface. In this figure, the results recorded by the strain gauges corresponded to the stirrup that first reached the yield strain. It shows an increase of stirrup strains with increasing slip. At the limit slip of $0.13 \mathrm{~mm}$ for interface shear failure suggested by Hanson (1960), stirrup stresses are still much lower than yield, even though at a slip of $0.5 \mathrm{~mm}$ (shear failure suggested by Loov and Patnaik (1994)), most stirrups cannot be expected to reach the average measured steel yield strain of $2187 \mu \varepsilon$. Interestingly, when reaching yield strain, the slips of specimens with the same LW slab concrete increase with the decreasing of clamping stress.

In Figure 12, the steel clamping component was calculated with the measured reinforcement strain $\varepsilon_{\mathrm{s}}$ and used a friction 


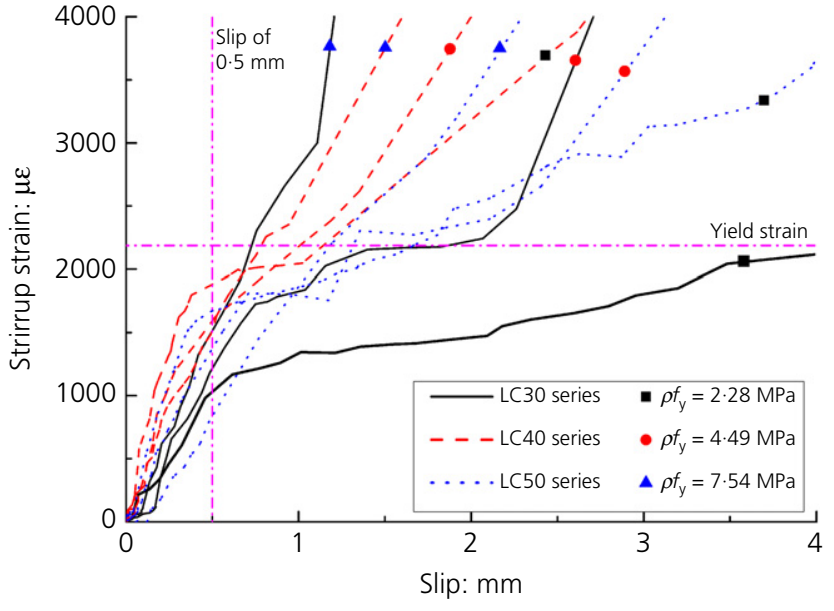

Figure 11. Typical slip-strain curves at the location of stirrups adjacent to the interface

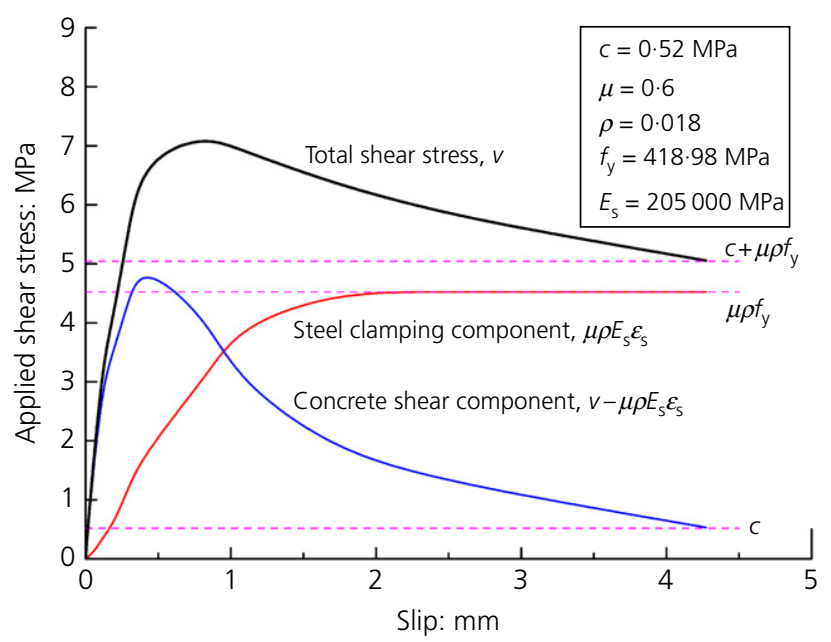

Figure 12. Typical component of shear friction behaviour factor $\mu$ of 0.6 which was consistent with AASHTO (2015). Thus, the component of reinforcement clamping force of shear friction is $\mu \rho E_{\mathrm{s}} \varepsilon_{\mathrm{s}}$. The concrete component was calculated by subtracting the reinforcement clamping component from the total shear stress $\left(v-\mu \rho E_{\mathrm{s}} \varepsilon_{\mathrm{s}}\right)$. After the yielding of the shear reinforcement, the steel component is equal to $\mu \rho f_{\mathrm{y}}$. Figure 12 also shows the nominal concrete component $c$, nominal steel component $\mu \rho f_{\mathrm{y}}$ and nominal total shear-friction interface shear stress $c+\mu \rho f_{\mathrm{y}}$.

As shown in Figure 12, the concrete component contributes to the major interface shear capacity before reaching the ultimate shear stress and then dropping to a residual value about the same as nominal concrete component $c$. For shear reinforcement component, it is lower than nominal value $\mu \rho f_{\mathrm{y}}$ at first but reaches this peak value well after exceeding the ultimate shear stress. This shows that the interface shear reinforcement yields after reaching peak shear stress, which has also been observed in other specimens. In other words, the maximum reinforcement and concrete component of shear friction have not occurred simultaneously, which is different from the case posited by shear-friction theory. It can also be seen in Figure 12 that the theory value of ultimate shear stress is lower than the experimental results, which may result from the underestimated value of the concrete component. The applicability of the shear-friction design code will be discussed in the next section.

\section{The equations for the interface shear capacity}

\section{The existing shear transfer equations}

Currently, several equations for predicting the ultimate resistance of the concrete-to-concrete interface have been proposed based on push-off specimens or beam test results (e.g. AASHTO, 2015; ACI, 2014; Harries et al., 2012; Kahn and Mitchell, 2002; Loov and Patnaik, 1994; Mattock et al., 1976; Walraven et al., 1987). However, few equations exist to

Table 5. Typical models for the interface shear capacity

\begin{tabular}{|c|c|c|c|c|}
\hline Equation & Reference & Predicting model & Limitation & Notation \\
\hline (1) & Mattock et al. (1976) & $v_{n}=1.4 \rho f_{y}+1.72$ & $0.2 f_{c}^{\prime}$ or $5.5 \mathrm{MPa}$ & $v_{n}$ : Interface shear stress \\
\hline (2) & Walraven et al. (1987) & $\begin{array}{l}v_{n}=C_{1}\left(\rho f_{\mathrm{y}}\right) C_{2} \\
\quad \text { where } C_{1}=0.878 f_{c}^{\prime 0.406} \\
C_{2}=0.167 f_{c}^{\prime 0.303}\end{array}$ & - & $\begin{array}{l}\rho: \text { Interface shear reinforcement ratios } \\
f_{\mathrm{y}}: \text { Yield strength of reinforcement } \\
f_{\mathrm{c}}^{\prime} \text { : Cylinder concrete strength } \\
k \cdot \text { Rouness }\end{array}$ \\
\hline (3) & $\begin{array}{l}\text { Loov and Patnaik } \\
\text { (1994) }\end{array}$ & $v_{n}=k \lambda \sqrt{\left(0 \cdot 1+\rho_{v} f_{\mathrm{y}}\right) f_{\mathrm{c}}^{\prime}}$ & $0.25 f_{c}^{\prime}$ & $\begin{array}{l}\lambda \text { : Correction factor related to concrete } \\
\text { density }\end{array}$ \\
\hline (4) & $\begin{array}{l}\text { Kahn and Mitchell } \\
\text { (2002) }\end{array}$ & $v_{n}=0.05 f_{\mathrm{c}}^{\prime}+1.4 \rho f_{\mathrm{y}}$ & $0 \cdot 2 f_{c}^{\prime}$ & $\begin{array}{l}\alpha_{0} \text { : Coefficient for interface condition } \\
E_{c} \text { : Elastic modulus of shear }\end{array}$ \\
\hline (5) & Harries et al. (2012) & $v_{n}=\alpha_{0} f_{\mathrm{c}}^{\prime}+0.002 \rho E_{\mathrm{s}}$ & $0 \cdot 2 f_{c}^{\prime}$ & reinforcement \\
\hline (6) & $\mathrm{ACl} 318-14(\mathrm{ACl}, 2014)$ & $v_{n}=\mu \rho f_{\mathrm{y}}$ & $0.2 f_{c}^{\prime}$ or $5.5 \mathrm{MPa}$ & $c_{0}:$ Cohesion coefficient \\
\hline (7) & $\begin{array}{l}\text { AASHTO (AASHTO, } \\
\text { 2015) }\end{array}$ & $v_{n}=c_{0}+\mu \rho f_{\mathrm{y}}$ & $\begin{array}{l}0.3 f_{c}^{\prime} \text { or } 9.0 \mathrm{MPa} \text { for } \\
\text { rough interface } \\
0.2 f_{c}^{\prime} \text { or } 5.5 \mathrm{MPa} \text { for } \\
\text { smooth interface }\end{array}$ & \\
\hline
\end{tabular}


Table 6. Comparisons of experimental results and existing equations

\begin{tabular}{|c|c|c|c|c|c|c|c|c|c|c|c|c|c|c|c|}
\hline \multirow[b]{2}{*}{ Specimens } & \multirow[b]{2}{*}{$\begin{array}{l}\text { Experimental } \\
\qquad v_{n}\end{array}$} & \multicolumn{2}{|c|}{ Mattock et al. (1976) } & \multicolumn{2}{|c|}{$\begin{array}{c}\text { Walraven et al. } \\
\text { (1987) }\end{array}$} & \multicolumn{2}{|c|}{$\begin{array}{l}\text { Loov and Patnaik } \\
\text { (1994) }\end{array}$} & \multicolumn{2}{|c|}{$\begin{array}{l}\text { Kahn and Mitchell } \\
\text { (2002) }\end{array}$} & \multicolumn{2}{|c|}{ Harries et al. (2012) } & \multicolumn{2}{|c|}{ ACI (2014) } & \multicolumn{2}{|c|}{ AASHTO (2015) } \\
\hline & & $v_{\text {Equation } 1}$ & $\begin{array}{c}v_{\text {Equation } 1} / \\
v_{n}\end{array}$ & $v_{\text {Equation 2 }}$ & $\begin{array}{c}v_{\text {Equation } 2 l} l \\
v_{n}\end{array}$ & $v_{\text {Equation } 3}$ & $\begin{array}{c}v_{\text {Equation } 3} / \\
v_{n}\end{array}$ & $v_{\text {Equation } 4}$ & $\begin{array}{c}v_{\text {Equation } 4} / \\
v_{n}\end{array}$ & $v_{\text {Equation } 5}$ & $\begin{array}{c}v_{\text {Equation } 5} / \\
v_{n}\end{array}$ & $v_{\text {Equation } 6}$ & $\begin{array}{c}v_{\text {Equation } 6} / \\
v_{n}\end{array}$ & $V_{\text {Equation } 7}$ & $\begin{array}{c}v_{\text {Equation } 7} / \\
v_{n}\end{array}$ \\
\hline S-C65L30-6D8-B & 3.37 & 3.54 & $1 \cdot 05$ & $5 \cdot 30$ & 1.57 & 4.44 & $1 \cdot 32$ & 4.78 & $1 \cdot 42$ & 4.43 & $1 \cdot 31$ & $1 \cdot 16$ & 0.34 & 1.89 & 0.56 \\
\hline S-C65L30-6D10-B & 5.57 & $5 \cdot 50$ & 0.99 & 7.66 & $1 \cdot 38$ & 6.46 & $1 \cdot 16$ & $6 \cdot 37$ & $1 \cdot 14$ & $6 \cdot 15$ & $1 \cdot 10$ & 2.52 & 0.45 & 3.48 & 0.63 \\
\hline S-C65L30-6D12-B & 7.03 & 5.50 & 0.78 & $9 \cdot 37$ & 1.33 & 7.95 & $1 \cdot 13$ & $6 \cdot 37$ & 0.91 & $6 \cdot 37$ & 0.91 & 3.85 & 0.55 & 5.04 & 0.72 \\
\hline S-C65L40-6D8-B & $3 \cdot 16$ & 3.54 & $1 \cdot 12$ & $6 \cdot 00$ & 1.90 & 4.99 & $1 \cdot 58$ & $5 \cdot 20$ & 1.65 & 4.76 & 1.51 & $1 \cdot 16$ & 0.37 & 1.89 & 0.60 \\
\hline S-C65L40-6D 10-B & $5 \cdot 16$ & 5.50 & 1.07 & 8.91 & 1.73 & $7 \cdot 26$ & 1.41 & 8.05 & 1.56 & $6 \cdot 48$ & $1 \cdot 26$ & 2.52 & 0.49 & 3.48 & 0.68 \\
\hline S-C65L40-6D12-B & 8.40 & 5.50 & 0.65 & 11.06 & $1 \cdot 32$ & 8.94 & 1.06 & 8.05 & 0.96 & 8.05 & 0.96 & 3.85 & 0.46 & 5.04 & 0.60 \\
\hline S-C65L50-6D8-B & $4 \cdot 13$ & 3.54 & 0.86 & 6.68 & 1.62 & $5 \cdot 51$ & 1.33 & 5.65 & $1 \cdot 37$ & $5 \cdot 12$ & $1 \cdot 24$ & $1 \cdot 16$ & 0.28 & 1.89 & 0.46 \\
\hline S-C65L50-6D10-B & 5.93 & 5.50 & 0.93 & $10 \cdot 17$ & $1 \cdot 72$ & 8.03 & $1 \cdot 35$ & $9 \cdot 37$ & $1 \cdot 58$ & 6.84 & $1 \cdot 15$ & 2.52 & 0.43 & 3.48 & 0.59 \\
\hline S-C65L50-6D12-B & 7.78 & 5.50 & 0.71 & $12 \cdot 79$ & 1.65 & 9.88 & $1 \cdot 27$ & 9.83 & $1 \cdot 26$ & $9 \cdot 35$ & $1 \cdot 20$ & 3.85 & 0.49 & 5.04 & 0.65 \\
\hline Mean & & 0.91 & & 1.58 & & $1 \cdot 29$ & & $1 \cdot 32$ & & $1 \cdot 18$ & & 0.43 & & 0.61 & \\
\hline Standard deviation & & $0 \cdot 16$ & & $0 \cdot 19$ & & 0.15 & & 0.25 & & 0.17 & & 0.08 & & 0.07 & \\
\hline Coefficient of variation & & 0.17 & & 0.12 & & 0.11 & & 0.19 & & 0.15 & & 0.18 & & 0.12 & \\
\hline R-C65L40-6D8-A & $6 \cdot 27$ & 3.54 & 0.57 & $5 \cdot 70$ & 0.91 & 3.97 & 0.63 & 5.02 & 0.80 & 4.62 & 0.74 & 1.94 & 0.31 & $4 \cdot 18$ & 0.67 \\
\hline R-C65L40-6D10-A & 9.49 & 5.50 & 0.58 & 8.37 & 0.88 & 5.77 & 0.16 & $7 \cdot 32$ & 0.77 & $6 \cdot 34$ & 0.67 & $4 \cdot 20$ & 0.44 & $6 \cdot 84$ & 0.72 \\
\hline R-C65L40-6D12-A & 9.31 & 5.50 & 0.59 & $10 \cdot 33$ & $1 \cdot 11$ & $7 \cdot 10$ & 0.76 & $7 \cdot 32$ & 0.79 & $7 \cdot 32$ & 0.79 & 5.50 & 0.59 & 9.00 & 0.97 \\
\hline R-C65L40-6D8-B & 6.08 & 3.54 & 0.58 & $5 \cdot 72$ & 0.94 & 3.98 & 0.65 & 5.03 & 0.83 & 4.62 & 0.76 & 1.94 & 0.32 & $4 \cdot 18$ & 0.69 \\
\hline R-C65L40-6D10-B & 9.52 & 5.50 & 0.58 & 8.41 & 0.88 & 5.79 & 0.61 & $7 \cdot 36$ & 0.77 & $6 \cdot 34$ & 0.67 & $4 \cdot 20$ & 0.44 & 6.84 & 0.72 \\
\hline R-C65L40-6D12-B & 9.96 & 5.50 & 0.55 & $10 \cdot 38$ & 1.04 & $7 \cdot 13$ & 0.72 & $7 \cdot 36$ & 0.74 & $7 \cdot 36$ & 0.74 & $5 \cdot 50$ & 0.55 & 9.00 & 0.90 \\
\hline Mean & & 0.57 & & 0.96 & & 0.66 & & 0.78 & & 0.73 & & 0.44 & & 0.78 & \\
\hline Standard deviation & & 0.01 & & 0.09 & & 0.06 & & 0.03 & & 0.04 & & 0.11 & & 0.11 & \\
\hline Coefficient of variation & & 0.02 & & 0.09 & & 0.09 & & 0.04 & & 0.06 & & 0.24 & & 0.15 & \\
\hline
\end{tabular}

Note: The mean, standard deviation and coefficient of variation are for the ratio of $v_{\text {Equation }(n) / V_{n}}$ 
determine the shear capacity of the interface between HS and LW concrete. Some typical equations for interface shear capacity prediction are listed in Table 5 . In order to assess the applicability of the preceding equations, the calculated results from the equations are shown in Table 6 . To be clearer, Table 6 also presents the ratios between the theoretical values predicted by the different equations and the experimental results.

From Table 6, it can be seen that the shear capacity for the smooth interface condition was underestimated by Equations 1,6 and 7 , with average $v_{\text {Equation }(x)} / v_{n}$ ratios ranging from $0 \cdot 43$ to $0 \cdot 61$. In contrast, Equations 2-5 gave comparatively unsafe results, with $v_{\text {Equation }(x)} / v_{n}$ ratios ranging from $1 \cdot 18$ to 1.58 for the smooth shear interface condition. However, all these equations showed safe results for specimens with rough interface condition.

Equation 1, the general formula proposed by Mattock et al. (1976) for the calculation of interface shear strength, is based on push-off specimens made with LW concrete. In this formula, the effect of clamping stress has been considered. Other contributions (e.g. cohesion effect or aggregate interlock action) have been included as a constant in the equation. It can also be noted that the limitation for this equation was quite conservative, causing safe predicting results.

The interface shear capacity of specimens in this study was seriously overestimated by Equations 2 and 3. For example, the ratio between prediction values obtained from Equation 2 and actual test results reached up to 1.58 for smooth interface specimens. These equations also considered the effect of concrete strength on interfacial shear capacity and adopted the parabolic equation forms. Equation 2 showed the best accuracy in predicting the ultimate resistance of specimens with rough interface condition.

Kahn and Mitchell (2002) proposed Equation 4 to extend the shear-friction concept to HS concrete, with the concrete strength varying from 46.9 to $123.4 \mathrm{MPa}$. This simple model took into account the effect of shear reinforcement and concrete strength. However, this equation was not applicable for calculating the interface shear resistance in the present study.

Equation 5 gave an acceptable prediction for interface shear capacity. Based on the study of Harries et al. (2012), reinforcement yielding should not be observed when the ultimate shear strength is reached. To establish a more rational basis, the clamping stress in this equation was a function of the elastic modulus rather than the yield strength of steel. Although this formula better reflected the actual mechanisms, it lost in terms of simplicity. Particularly, this equation was developed based on shear-friction testing with HS steel.

The applicability of current design codes (Equations 6 and 7) have been discussed in detail in the previous study focusing on rough interfaces (Jiang et al., 2016b). It can be noted that both the ACI and AASHTO design codes also seriously underestimated the shear resistance of the interface between HS and LW concrete with smooth interface, with average $v_{\text {Equation }(x)} / v_{n}$ ratios of 0.43 and $0 \cdot 61$, respectively.

\section{Proposed shear capacity equation and verification}

As mentioned previously, the capacity of specimens presented in this study can rarely be well predicted using existing equations. Thus, a more applicable model is necessary for predicting the shear strength of interfaces between HS and LW concrete. Similar to the proposals of several authors, multiple regression analysis was performed to propose an equation adjusted to the results presented in this study. Equations listed in Table 5 are used as a basis for modification to account for the effect of concrete strength and clamping stress. The proposed shear capacity equation is composed as described in Equation 8, incorporating a component for bond and interlock action $\left(\alpha f_{\mathrm{c}}^{\prime}\right)$ and a friction component of clamping stress $\left(\rho f_{\mathrm{y}}\right)$

\section{8. $v_{n}=\alpha f_{\mathrm{c}}^{\prime}+\beta \rho f_{\mathrm{y}}$}

where $\alpha$ and $\beta$ are values acquired by the regression analysis on the experimental results. Therefore, the value of $\alpha=0.04$ and $\beta=0.8$ for the smooth interface condition, and $\alpha=0.04$ and $\beta=1.4$ for the rough interface condition can be obtained.

For the smooth interface condition

9. $v_{n}=0.04 f_{\mathrm{c}}^{\prime}+0 \cdot 8 \rho f_{\mathrm{y}}$

but not more than $K_{1} f_{\mathrm{c}}^{\prime}$ or $K_{2}$.

For the rough interface condition

10. $v_{n}=0.05 f_{\mathrm{c}}^{\prime}+1 \cdot 4 \rho f_{\mathrm{y}}$

but not more than $K_{3} f_{\mathrm{c}}^{\prime}$ or $K_{4}$.

Similar to that used by AASHTO (2015), ACI 318-14 (ACI, 2014) or other researchers (e.g. Harries et al., 2012; Kahn and Mitchell, 2002; Loov and Patnaik, 1994; Mattock et al., 1976), an upper limit for the shear strength was set to agree well with the experimental data: for the smooth interface condition, $K_{1}=0 \cdot 2$ and $K_{2}=9 \mathrm{MPa}$ for LW, NW and HS concrete; for LW concrete with rough interface condition, $K_{3}=0 \cdot 3$ and $K_{4}=9 \mathrm{MPa}$; for $\mathrm{NW}$ concrete with rough interface condition, $K_{3}=0.3$ and $K_{4}=12 \mathrm{MPa}$; while for the case of HS concrete with rough interface condition, $K_{3}=0 \cdot 3$ and $K_{4}=15 \mathrm{MPa}$. For both smooth and rough interface conditions, the predicted results show a good agreement with those obtained from experimental and analytical values. For the smooth interface condition, the mean value and standard deviation between 
Table 7. Shear friction in push-off specimens with smooth interface condition

\begin{tabular}{|c|c|c|c|c|c|c|c|}
\hline Reference & Specimens & Concrete type & $f_{\mathrm{c}}^{\prime}: \mathrm{MPa}$ & $\rho f_{y}: \mathrm{MPa}$ & v: MPa & $v_{\text {Equation }} 9$ & $v_{\text {Equation } 9} / v$ \\
\hline \multirow[t]{20}{*}{ Hofbeck and Ibrahim (1969) } & $2 \cdot 10$ & NW & $21 \cdot 37$ & 1.54 & 4.07 & 2.09 & 0.51 \\
\hline & $2 \cdot 2$ & NW & $21 \cdot 37$ & 3.08 & 4.69 & $3 \cdot 32$ & 0.71 \\
\hline & $2 \cdot 3$ & NW & $26 \cdot 89$ & $4 \cdot 62$ & $5 \cdot 79$ & $4 \cdot 77$ & 0.82 \\
\hline & $2 \cdot 4$ & NW & $26 \cdot 89$ & $6 \cdot 16$ & $6 \cdot 90$ & $6 \cdot 00$ & $0 \cdot 87$ \\
\hline & $2 \cdot 5$ & NW & $28 \cdot 82$ & $7 \cdot 72$ & 8.96 & $7 \cdot 33$ & $0 \cdot 82$ \\
\hline & $2 \cdot 6$ & NW & $28 \cdot 82$ & $9 \cdot 24$ & $9 \cdot 55$ & $8 \cdot 54$ & 0.89 \\
\hline & $3 \cdot 2$ & NW & $27 \cdot 65$ & $1 \cdot 54$ & 3.59 & $2 \cdot 34$ & 0.65 \\
\hline & $3 \cdot 3$ & NW & $21 \cdot 37$ & $3 \cdot 08$ & $4 \cdot 69$ & $3 \cdot 32$ & 0.71 \\
\hline & $3 \cdot 4$ & NW & $27 \cdot 86$ & $5 \cdot 10$ & 7.09 & $5 \cdot 20$ & 0.73 \\
\hline & $3 \cdot 5$ & NW & $27 \cdot 86$ & $7 \cdot 17$ & $7 \cdot 94$ & $6 \cdot 85$ & 0.86 \\
\hline & $4 \cdot 1$ & NW & 28.06 & $2 \cdot 02$ & $4 \cdot 85$ & $2 \cdot 74$ & 0.56 \\
\hline & $4 \cdot 2$ & NW & 28.06 & 4.02 & $6 \cdot 76$ & $4 \cdot 34$ & 0.64 \\
\hline & $4 \cdot 3$ & NW & $29 \cdot 92$ & 6.03 & $8 \cdot 14$ & $6 \cdot 02$ & $0 \cdot 74$ \\
\hline & $4 \cdot 4$ & NW & $29 \cdot 92$ & 8.03 & $9 \cdot 65$ & $7 \cdot 62$ & 0.79 \\
\hline & $4 \cdot 5$ & NW & $30 \cdot 27$ & $10 \cdot 03$ & $9 \cdot 10$ & $9 \cdot 00$ & 0.99 \\
\hline & $5 \cdot 1$ & NW & $16 \cdot 89$ & 1.54 & $3 \cdot 52$ & 1.91 & 0.54 \\
\hline & $5 \cdot 2$ & NW & 18.06 & 3.08 & 4.83 & $3 \cdot 18$ & 0.66 \\
\hline & $5 \cdot 3$ & NW & $16 \cdot 44$ & $4 \cdot 62$ & $5 \cdot 58$ & $4 \cdot 35$ & 0.78 \\
\hline & 5.4 & NW & $17 \cdot 79$ & $6 \cdot 16$ & $5 \cdot 48$ & $5 \cdot 64$ & 1.03 \\
\hline & $5 \cdot 5$ & NW & $18 \cdot 06$ & $7 \cdot 72$ & $6 \cdot 96$ & $6 \cdot 90$ & 0.99 \\
\hline \multirow[t]{18}{*}{ Mattock et al. (1976) } & B1 & LC & $25 \cdot 79$ & $1 \cdot 50$ & $3 \cdot 10$ & $2 \cdot 23$ & $0 \cdot 72$ \\
\hline & B2 & LC & $23 \cdot 17$ & 3.09 & $4 \cdot 50$ & $3 \cdot 40$ & 0.76 \\
\hline & B3 & LC & $26 \cdot 96$ & $4 \cdot 63$ & $5 \cdot 79$ & 4.79 & 0.83 \\
\hline & B4 & LC & $28 \cdot 27$ & $5 \cdot 96$ & $6 \cdot 48$ & $5 \cdot 65$ & $0 \cdot 87$ \\
\hline & B5 & LC & $27 \cdot 30$ & $7 \cdot 66$ & $6 \cdot 90$ & $5 \cdot 46$ & $0 \cdot 79$ \\
\hline & B6 & LC & $29 \cdot 30$ & $9 \cdot 43$ & $7 \cdot 96$ & $5 \cdot 86$ & $0 \cdot 74$ \\
\hline & D1 & LC & $41 \cdot 34$ & $1 \cdot 57$ & 2.55 & $2 \cdot 91$ & $1 \cdot 14$ \\
\hline & D2 & LC & $41 \cdot 34$ & $3 \cdot 17$ & $4 \cdot 61$ & $4 \cdot 19$ & 0.91 \\
\hline & D3 & LC & $39 \cdot 37$ & $4 \cdot 76$ & $5 \cdot 32$ & $5 \cdot 38$ & 1.01 \\
\hline & D4 & LC & $39 \cdot 37$ & $6 \cdot 34$ & $7 \cdot 05$ & $6 \cdot 65$ & 0.94 \\
\hline & D5 & LC & $38 \cdot 61$ & $7 \cdot 94$ & $7 \cdot 46$ & $7 \cdot 72$ & 1.03 \\
\hline & D6 & LC & $38 \cdot 61$ & $9 \cdot 43$ & 8.41 & $7 \cdot 72$ & 0.92 \\
\hline & N1 & NW & $28 \cdot 82$ & $1 \cdot 54$ & $3 \cdot 17$ & $2 \cdot 39$ & $0 \cdot 75$ \\
\hline & N2 & NW & $26 \cdot 89$ & $3 \cdot 20$ & $5 \cdot 38$ & $3 \cdot 64$ & 0.68 \\
\hline & N3 & NW & $27 \cdot 55$ & $4 \cdot 76$ & 6.62 & 4.91 & 0.74 \\
\hline & N4 & NW & $28 \cdot 61$ & $6 \cdot 18$ & 7.93 & $5 \cdot 72$ & 0.72 \\
\hline & N5 & NW & $27 \cdot 13$ & $7 \cdot 72$ & $8 \cdot 10$ & 5.43 & 0.67 \\
\hline & N6 & NW & $28 \cdot 41$ & $9 \cdot 10$ & $8 \cdot 21$ & $5 \cdot 68$ & 0.69 \\
\hline \multirow[t]{18}{*}{ Hoff (1992) } & LWC 1-1 & LC & $58 \cdot 54$ & 1.94 & 1.98 & $3 \cdot 89$ & 1.97 \\
\hline & LWC 1-2 & LC & $58 \cdot 68$ & 1.94 & $2 \cdot 52$ & 3.90 & $1 \cdot 55$ \\
\hline & LWC 1-3 & LC & $57 \cdot 16$ & 1.94 & $2 \cdot 85$ & $3 \cdot 84$ & $1 \cdot 35$ \\
\hline & LWC 1-4 & LC & $58 \cdot 54$ & $4 \cdot 47$ & $5 \cdot 25$ & $5 \cdot 92$ & $1 \cdot 13$ \\
\hline & LWC 1-5 & LC & $58 \cdot 68$ & $4 \cdot 53$ & $4 \cdot 69$ & $5 \cdot 97$ & $1 \cdot 27$ \\
\hline & LWC1-6 & LC & $57 \cdot 16$ & $4 \cdot 47$ & $5 \cdot 01$ & $5 \cdot 86$ & $1 \cdot 17$ \\
\hline & LWC2-1 & LC & $63 \cdot 92$ & 1.93 & $3 \cdot 37$ & $4 \cdot 10$ & $1 \cdot 22$ \\
\hline & LWC2-2 & LC & $60 \cdot 40$ & 1.93 & $2 \cdot 31$ & 3.96 & $1 \cdot 71$ \\
\hline & LWC2-3 & LC & $60 \cdot 19$ & 1.93 & 2.06 & 3.95 & 1.92 \\
\hline & LWC2-4 & LC & $57 \cdot 02$ & $4 \cdot 47$ & $5 \cdot 10$ & $5 \cdot 86$ & $1 \cdot 15$ \\
\hline & LWC2-5 & LC & $60 \cdot 40$ & $4 \cdot 50$ & $4 \cdot 77$ & $6 \cdot 01$ & $1 \cdot 26$ \\
\hline & LWC2-6 & LC & $60 \cdot 19$ & $4 \cdot 50$ & $4 \cdot 69$ & $6 \cdot 00$ & $1 \cdot 28$ \\
\hline & LWC3-1 & LC & 71.09 & $2 \cdot 61$ & $4 \cdot 61$ & 4.93 & 1.07 \\
\hline & LWC3-2 & LC & $75 \cdot 22$ & $2 \cdot 61$ & $3 \cdot 78$ & 5.09 & $1 \cdot 35$ \\
\hline & LWC3-3 & LC & $75 \cdot 98$ & $2 \cdot 61$ & 4.03 & $5 \cdot 12$ & $1 \cdot 27$ \\
\hline & LWC3-4 & LC & 71.09 & $4 \cdot 36$ & $6 \cdot 00$ & $6 \cdot 33$ & 1.06 \\
\hline & LWC3-5 & LC & $75 \cdot 22$ & $4 \cdot 41$ & $6 \cdot 00$ & $6 \cdot 54$ & 1.09 \\
\hline & LWC3-6 & LC & $75 \cdot 98$ & $4 \cdot 39$ & $6 \cdot 16$ & $6 \cdot 55$ & 1.06 \\
\hline \multirow[t]{5}{*}{ Kahn and Mitchell (2002) } & SF-10-1-CJ & HS & $98 \cdot 78$ & $2 \cdot 10$ & $3 \cdot 65$ & $5 \cdot 63$ & $1 \cdot 54$ \\
\hline & SF-10-2-CJ & HS & $83 \cdot 11$ & $4 \cdot 20$ & $5 \cdot 67$ & $6 \cdot 68$ & $1 \cdot 18$ \\
\hline & SF-4-1-C & NW & $46 \cdot 92$ & $1 \cdot 76$ & 4.02 & $3 \cdot 28$ & $0 \cdot 82$ \\
\hline & SF-4-2-C & NW & $46 \cdot 92$ & $3 \cdot 52$ & $6 \cdot 40$ & $4 \cdot 69$ & 0.73 \\
\hline & SF-4-3-C & NW & $46 \cdot 92$ & $5 \cdot 27$ & $8 \cdot 18$ & $6 \cdot 10$ & 0.75 \\
\hline
\end{tabular}


Table 7. Continued

\begin{tabular}{|c|c|c|c|c|c|c|c|}
\hline Reference & Specimens & Concrete type & $f_{\mathrm{c}}^{\prime}: \mathrm{MPa}$ & $\rho f_{\mathrm{y}}: \mathrm{MPa}$ & v: MPa & $v_{\text {Equation } 9}$ & $v_{\text {Equation } 9} / v$ \\
\hline & SF-7-1-C & $\mathrm{HS}$ & $80 \cdot 91$ & $2 \cdot 10$ & $4 \cdot 79$ & $4 \cdot 91$ & 1.03 \\
\hline & SF-7-2-C & HS & $85 \cdot 57$ & $4 \cdot 20$ & $5 \cdot 94$ & $6 \cdot 78$ & $1 \cdot 14$ \\
\hline & SF-7-3-C & $\mathrm{HS}$ & $90 \cdot 35$ & $6 \cdot 30$ & $8 \cdot 22$ & 8.65 & 1.05 \\
\hline & SF-7-4-C & $\mathrm{HS}$ & 85.99 & $8 \cdot 39$ & $7 \cdot 21$ & $9 \cdot 00$ & $1 \cdot 25$ \\
\hline & SF-10-1-Ca & HS & $83 \cdot 11$ & $2 \cdot 10$ & $2 \cdot 96$ & $5 \cdot 00$ & 1.69 \\
\hline & SF-10-1-Cb & $\mathrm{HS}$ & $98 \cdot 78$ & $2 \cdot 10$ & $3 \cdot 45$ & $5 \cdot 63$ & 1.63 \\
\hline & SF-10-2-Ca & HS & $101 \cdot 19$ & $4 \cdot 20$ & $5 \cdot 83$ & $7 \cdot 41$ & $1 \cdot 27$ \\
\hline & SF-10-2-Cb & HS & $102 \cdot 07$ & $4 \cdot 20$ & $5 \cdot 53$ & $7 \cdot 44$ & $1 \cdot 35$ \\
\hline & SF-10-3-Ca & $\mathrm{HS}$ & $111 \cdot 49$ & $6 \cdot 30$ & $7 \cdot 43$ & $9 \cdot 00$ & $1 \cdot 21$ \\
\hline & SF-10-3-Cb & HS & 96.07 & $6 \cdot 30$ & $7 \cdot 28$ & $8 \cdot 88$ & $1 \cdot 22$ \\
\hline & SF-10-4-Ca & $\mathrm{HS}$ & $106 \cdot 65$ & $8 \cdot 39$ & $8 \cdot 52$ & 9.00 & 1.06 \\
\hline & SF-10-4-Cb & $\mathrm{HS}$ & $113 \cdot 60$ & $8 \cdot 39$ & $8 \cdot 76$ & $9 \cdot 00$ & 1.03 \\
\hline & SF-14-1-C & $\mathrm{HS}$ & $110 \cdot 42$ & $2 \cdot 10$ & $2 \cdot 86$ & 6.09 & $2 \cdot 13$ \\
\hline & SF-14-2-C & HS & $106 \cdot 84$ & $4 \cdot 20$ & $4 \cdot 62$ & $7 \cdot 63$ & 1.65 \\
\hline & SF-14-3-C & $\mathrm{HS}$ & $106 \cdot 13$ & $6 \cdot 30$ & $6 \cdot 38$ & $9 \cdot 00$ & $1 \cdot 41$ \\
\hline & SF-14-4-C & $\mathrm{HS}$ & $110 \cdot 20$ & $8 \cdot 39$ & $8 \cdot 42$ & $9 \cdot 00$ & 1.07 \\
\hline \multirow[t]{12}{*}{ Shaw and Sneed (2014) } & S-5-S-1 & LC & $31 \cdot 37$ & $6 \cdot 06$ & $5 \cdot 38$ & $6 \cdot 10$ & $1 \cdot 13$ \\
\hline & S-5-S-2 & LC & $31 \cdot 37$ & 6.06 & $4 \cdot 76$ & $6 \cdot 10$ & $1 \cdot 28$ \\
\hline & $S-5-S-3$ & LC & $31 \cdot 37$ & 6.06 & $5 \cdot 52$ & $6 \cdot 10$ & $1 \cdot 11$ \\
\hline & S-8-S-1 & LC & $49 \cdot 71$ & $6 \cdot 06$ & $9 \cdot 31$ & $6 \cdot 84$ & 0.73 \\
\hline & $S-8-S-2$ & LC & $49 \cdot 71$ & 6.06 & 8.07 & $6 \cdot 84$ & 0.85 \\
\hline & $S-8-S-3$ & LC & $49 \cdot 71$ & 6.06 & $8 \cdot 21$ & $6 \cdot 84$ & 0.83 \\
\hline & $N-5-S-4$ & NW & $33 \cdot 51$ & 6.06 & $4 \cdot 55$ & $6 \cdot 19$ & $1 \cdot 36$ \\
\hline & $N-5-S-5$ & NW & $33 \cdot 51$ & $6 \cdot 06$ & $4 \cdot 83$ & $6 \cdot 19$ & $1 \cdot 28$ \\
\hline & $N-5-S-6$ & NW & $33 \cdot 51$ & 6.06 & $5 \cdot 45$ & $6 \cdot 19$ & $1 \cdot 14$ \\
\hline & $N-8-S-1$ & NW & $52 \cdot 06$ & 6.06 & $9 \cdot 10$ & $6 \cdot 93$ & 0.76 \\
\hline & $\mathrm{N}-8-\mathrm{S}-2$ & NW & $52 \cdot 06$ & $6 \cdot 06$ & $7 \cdot 45$ & $6 \cdot 93$ & 0.93 \\
\hline & $N-8-S-3$ & NW & $52 \cdot 06$ & 6.06 & $7 \cdot 72$ & 6.93 & 0.90 \\
\hline \multirow[t]{16}{*}{ Sneed et al. (2016) } & S-SL-CJ-S-9-1 & LC & $37 \cdot 10$ & $4 \cdot 48$ & $3 \cdot 72$ & $5 \cdot 07$ & $1 \cdot 36$ \\
\hline & S-SL-CJ-S-9-2 & LC & $37 \cdot 10$ & $4 \cdot 48$ & $4 \cdot 55$ & $5 \cdot 07$ & $1 \cdot 11$ \\
\hline & S-SL-CJ-S-13-1 & LC & $38 \cdot 41$ & $6 \cdot 47$ & $5 \cdot 50$ & $6 \cdot 72$ & $1 \cdot 22$ \\
\hline & S-SL-CJ-S-13-2 & LC & $38 \cdot 41$ & $6 \cdot 47$ & $6 \cdot 79$ & $6 \cdot 72$ & 0.99 \\
\hline & S-SL-CJ-S-17-1 & LC & $34 \cdot 13$ & 8.47 & $6 \cdot 62$ & $6 \cdot 83$ & 1.03 \\
\hline & S-SL-CJ-S-17-2 & LC & $34 \cdot 13$ & $8 \cdot 47$ & $6 \cdot 55$ & $6 \cdot 83$ & 1.04 \\
\hline & S-SL-CJ-S-22-1 & LC & $34 \cdot 48$ & $10 \cdot 96$ & $6 \cdot 96$ & $6 \cdot 90$ & 0.99 \\
\hline & S-SL-CJ-S-22-2 & LC & $34 \cdot 48$ & $10 \cdot 96$ & $7 \cdot 86$ & $6 \cdot 90$ & 0.88 \\
\hline & S-CL-CJ-S-9-1 & LC & $32 \cdot 89$ & $4 \cdot 48$ & $4 \cdot 48$ & $4 \cdot 90$ & 1.09 \\
\hline & S-CL-CJ-S-9-2 & LC & $32 \cdot 89$ & $4 \cdot 48$ & $5 \cdot 31$ & $4 \cdot 90$ & 0.92 \\
\hline & S-CL-CJ-S-13-1 & LC & 31.99 & $6 \cdot 47$ & $5 \cdot 71$ & $6 \cdot 40$ & $1 \cdot 12$ \\
\hline & S-CL-CJ-S-13-2 & LC & 31.99 & $6 \cdot 47$ & $5 \cdot 63$ & $6 \cdot 40$ & $1 \cdot 14$ \\
\hline & S-CL-CJ-S-17-1 & LC & $31 \cdot 37$ & $8 \cdot 47$ & 6.00 & $6 \cdot 27$ & 1.05 \\
\hline & S-CL-CJ-S-17-2 & LC & $31 \cdot 37$ & $8 \cdot 47$ & $6 \cdot 83$ & $6 \cdot 27$ & 0.92 \\
\hline & S-CL-CJ-S-22-1 & LC & $39 \cdot 92$ & $10 \cdot 96$ & $7 \cdot 30$ & $7 \cdot 98$ & 1.09 \\
\hline & S-CL-CJ-S-22-2 & LC & $39 \cdot 92$ & $10 \cdot 96$ & $7 \cdot 32$ & $7 \cdot 98$ & 1.09 \\
\hline
\end{tabular}

experimental and predicted value using Equation 9 are 0.99 and $0 \cdot 07$, respectively, while for the rough interface condition the relation and standard deviation between experimental and predicted value using Equation 10 are 0.96 and $0 \cdot 14$, respectively.

\section{Validation of the proposed equation}

In order to assess the applicability of Equations 9 and 10, the related experimental results obtained by Hofbeck and Ibrahim (1969), Mattock (1976), Mattock et al. (1976), Hoff (1992),
Kahn and Mitchell (2002), Mansur et al. (2008), Shaw and Sneed (2014) and Sneed et al. (2016) were considered. The source and specimen results for $v$ are listed in Tables 7 and 8, including results for LW concrete specimens, NW concrete specimens and HS concrete specimens. Figure 13 shows a comparison of experimental and predicted results. It can be seen that Equation 9 gave a conservative predicted result for NW specimens with a value of 0.81 for the mean of predicted/experimental results. In contrast, Equation 9 represented acceptable overestimated results for LW and HS specimens with rough shear plane. For the rough interface 
Table 8. Shear friction in push-off specimens with rough interface condition

\begin{tabular}{|c|c|c|c|c|c|c|c|}
\hline Reference & Specimens & Concrete type & $f_{c:}^{\prime}: M P a$ & $\rho f_{\mathrm{y}}: \mathrm{MPa}$ & v: MPa & $v_{\text {Equation }} 10$ & $v_{\text {Equation } 10} / v$ \\
\hline \multirow[t]{14}{*}{ Mattock et al. (1976) } & $\mathrm{AO}$ & LW & $29 \cdot 17$ & 0.00 & $3 \cdot 45$ & $1 \cdot 46$ & 0.42 \\
\hline & A1 & LW & $25 \cdot 79$ & 1.45 & $5 \cdot 23$ & $3 \cdot 32$ & 0.63 \\
\hline & $\mathrm{A} 2$ & LW & $28 \cdot 24$ & $3 \cdot 25$ & $6 \cdot 30$ & $5 \cdot 97$ & 0.95 \\
\hline & A3 & LW & $26 \cdot 96$ & $4 \cdot 84$ & $7 \cdot 03$ & 8.09 & $1 \cdot 15$ \\
\hline & A4 & LW & $28 \cdot 27$ & $6 \cdot 18$ & $7 \cdot 58$ & 8.48 & $1 \cdot 12$ \\
\hline & A5 & LW & $27 \cdot 30$ & $7 \cdot 72$ & $8 \cdot 21$ & $8 \cdot 19$ & 1.00 \\
\hline & A6 & LW & $29 \cdot 30$ & $9 \cdot 43$ & $9 \cdot 27$ & 8.79 & 0.95 \\
\hline & MO & NW & $27 \cdot 13$ & 0.00 & 4.07 & $1 \cdot 36$ & 0.33 \\
\hline & M1 & NW & $28 \cdot 82$ & 1.54 & $5 \cdot 24$ & $3 \cdot 60$ & 0.69 \\
\hline & $\mathrm{M} 2$ & NW & $26 \cdot 89$ & $3 \cdot 20$ & $6 \cdot 76$ & $5 \cdot 82$ & 0.86 \\
\hline & M3 & NW & $27 \cdot 55$ & $4 \cdot 76$ & $7 \cdot 65$ & 8.04 & 1.05 \\
\hline & M4 & NW & 28.61 & $6 \cdot 18$ & $7 \cdot 86$ & 8.58 & 1.09 \\
\hline & M5 & NW & $27 \cdot 13$ & 8.00 & $8 \cdot 48$ & $8 \cdot 14$ & 0.96 \\
\hline & M6 & NW & $28 \cdot 41$ & $9 \cdot 60$ & $9 \cdot 10$ & $8 \cdot 52$ & 0.94 \\
\hline \multirow[t]{11}{*}{ Mattock (1976) } & B1 & NW & $40 \cdot 27$ & 1.56 & $3 \cdot 36$ & $4 \cdot 19$ & $1 \cdot 25$ \\
\hline & B2 & NW & $40 \cdot 27$ & $3 \cdot 07$ & $4 \cdot 83$ & $6 \cdot 31$ & $1 \cdot 31$ \\
\hline & B3 & NW & $41 \cdot 75$ & $4 \cdot 66$ & $7 \cdot 27$ & $8 \cdot 61$ & $1 \cdot 19$ \\
\hline & B4 & NW & $41 \cdot 75$ & $6 \cdot 53$ & $8 \cdot 80$ & $11 \cdot 23$ & $1 \cdot 28$ \\
\hline & B5 & NW & 40.65 & $8 \cdot 70$ & $10 \cdot 83$ & $12 \cdot 00$ & $1 \cdot 11$ \\
\hline & B6 & NW & 40.65 & $10 \cdot 87$ & $11 \cdot 72$ & $12 \cdot 00$ & 1.02 \\
\hline & D1 & NW & $25 \cdot 99$ & 1.55 & 4.07 & $3 \cdot 47$ & 0.85 \\
\hline & D2 & NW & 25.99 & $3 \cdot 11$ & $6 \cdot 34$ & 5.65 & 0.89 \\
\hline & D3 & NW & $20 \cdot 27$ & $5 \cdot 10$ & $6 \cdot 96$ & $6 \cdot 08$ & 0.87 \\
\hline & D4A & NW & $17 \cdot 20$ & $6 \cdot 55$ & $6 \cdot 85$ & $5 \cdot 16$ & 0.75 \\
\hline & D4 & NW & $20 \cdot 27$ & $6 \cdot 79$ & $6 \cdot 91$ & $6 \cdot 08$ & 0.88 \\
\hline \multirow{10}{*}{ Kahn and Mitchell (2002) } & SF-7-1-CJ & HS & 80.91 & $2 \cdot 10$ & $6 \cdot 21$ & $6 \cdot 98$ & $1 \cdot 12$ \\
\hline & SF-7-2-CJ & $\mathrm{HS}$ & $80 \cdot 91$ & $4 \cdot 20$ & $9 \cdot 43$ & $9 \cdot 92$ & 1.05 \\
\hline & SF-7-3-CJ & $\mathrm{HS}$ & 85.99 & $6 \cdot 30$ & $12 \cdot 67$ & $13 \cdot 11$ & 1.03 \\
\hline & SF-7-4-CJ & $\mathrm{HS}$ & 85.99 & $8 \cdot 39$ & $15 \cdot 24$ & $15 \cdot 00$ & 0.98 \\
\hline & SF-10-3-CJ & $\mathrm{HS}$ & $89 \cdot 31$ & $6 \cdot 30$ & $13 \cdot 09$ & $13 \cdot 28$ & 1.01 \\
\hline & SF-10-4-CJ & $\mathrm{HS}$ & $89 \cdot 31$ & $8 \cdot 39$ & 14.49 & $15 \cdot 00$ & 1.04 \\
\hline & SF-14-1-CJ & $\mathrm{HS}$ & $101 \cdot 74$ & $2 \cdot 10$ & $10 \cdot 45$ & 8.02 & 0.77 \\
\hline & SF-14-2-CJ & $\mathrm{HS}$ & $101 \cdot 74$ & $4 \cdot 20$ & $11 \cdot 40$ & $10 \cdot 97$ & 0.96 \\
\hline & SF-14-3-CJ & $\mathrm{HS}$ & 104.93 & $6 \cdot 30$ & $15 \cdot 48$ & 14.06 & 0.91 \\
\hline & SF-14-4-CJ & HS & $104 \cdot 93$ & $8 \cdot 39$ & $17 \cdot 60$ & $15 \cdot 00$ & 0.85 \\
\hline \multirow[t]{19}{*}{ Mansur et al. (2008) } & AN-2 & NW & $40 \cdot 20$ & $4 \cdot 71$ & $8 \cdot 18$ & $8 \cdot 60$ & 1.05 \\
\hline & AN-4 & NW & $40 \cdot 20$ & $9 \cdot 42$ & $10 \cdot 17$ & $12 \cdot 06$ & $1 \cdot 19$ \\
\hline & AN-6 & NW & $40 \cdot 20$ & $14 \cdot 13$ & $12 \cdot 92$ & $12 \cdot 06$ & 0.93 \\
\hline & $\mathrm{AM}-2$ & $\mathrm{HS}$ & $69 \cdot 00$ & $4 \cdot 71$ & $7 \cdot 50$ & $10 \cdot 04$ & $1 \cdot 34$ \\
\hline & AM-3 & $\mathrm{HS}$ & $69 \cdot 00$ & $7 \cdot 07$ & $11 \cdot 50$ & $13 \cdot 35$ & $1 \cdot 16$ \\
\hline & AM-4 & $\mathrm{HS}$ & $69 \cdot 00$ & $9 \cdot 42$ & 14.03 & $15 \cdot 00$ & 1.07 \\
\hline & $\mathrm{AH}-2$ & $\mathrm{HS}$ & $87 \cdot 00$ & $4 \cdot 71$ & $7 \cdot 78$ & $10 \cdot 94$ & $1 \cdot 41$ \\
\hline & $\mathrm{AH}-3$ & $\mathrm{HS}$ & $87 \cdot 00$ & $7 \cdot 07$ & $12 \cdot 36$ & $14 \cdot 25$ & $1 \cdot 15$ \\
\hline & $\mathrm{AH}-4$ & $\mathrm{HS}$ & $87 \cdot 00$ & $9 \cdot 42$ & $14 \cdot 17$ & $15 \cdot 00$ & 1.06 \\
\hline & B1-4 & $\mathrm{HS}$ & $73 \cdot 20$ & $2 \cdot 67$ & $6 \cdot 73$ & $7 \cdot 40$ & $1 \cdot 10$ \\
\hline & B2-2 & $\mathrm{HS}$ & 84.90 & $1 \cdot 34$ & $5 \cdot 17$ & $6 \cdot 12$ & $1 \cdot 18$ \\
\hline & B2-4 & $\mathrm{HS}$ & $84 \cdot 90$ & $2 \cdot 67$ & $7 \cdot 32$ & $7 \cdot 98$ & 1.09 \\
\hline & B2-5 & $\mathrm{HS}$ & 84.90 & $3 \cdot 36$ & $8 \cdot 21$ & 8.95 & 1.09 \\
\hline & B2-6 & $\mathrm{HS}$ & 84.90 & 4.02 & $9 \cdot 17$ & $9 \cdot 87$ & 1.08 \\
\hline & B3-4 & $\mathrm{HS}$ & $95 \cdot 20$ & $2 \cdot 67$ & $7 \cdot 97$ & $8 \cdot 50$ & 1.07 \\
\hline & B4-2 & $\mathrm{HS}$ & $106 \cdot 40$ & $1 \cdot 34$ & $6 \cdot 01$ & $7 \cdot 20$ & $1 \cdot 20$ \\
\hline & B4-4 & $\mathrm{HS}$ & $106 \cdot 40$ & $2 \cdot 67$ & 8.43 & 9.06 & 1.07 \\
\hline & B4-5 & $\mathrm{HS}$ & $106 \cdot 40$ & $3 \cdot 36$ & $9 \cdot 24$ & $10 \cdot 02$ & 1.08 \\
\hline & B4-6 & $\mathrm{HS}$ & $106 \cdot 40$ & 4.02 & $9 \cdot 96$ & $10 \cdot 95$ & $1 \cdot 10$ \\
\hline \multirow[t]{7}{*}{ Shaw and Sneed (2014) } & $S-5-R-1$ & LW & $31 \cdot 37$ & 6.06 & $7 \cdot 17$ & $9 \cdot 00$ & $1 \cdot 26$ \\
\hline & S-5-R-2 & LW & $31 \cdot 37$ & 6.06 & 7.03 & 9.00 & $1 \cdot 28$ \\
\hline & $S-5-R-3$ & LW & $31 \cdot 37$ & 6.06 & $7 \cdot 52$ & $9 \cdot 00$ & $1 \cdot 20$ \\
\hline & S-8-R-1 & LW & $49 \cdot 71$ & 6.06 & $10 \cdot 07$ & 9.00 & 0.89 \\
\hline & S-8-R-2 & LW & $49 \cdot 71$ & 6.06 & $9 \cdot 38$ & 9.00 & 0.96 \\
\hline & $S-8-R-3$ & LW & $49 \cdot 71$ & $6 \cdot 06$ & $9 \cdot 31$ & $9 \cdot 00$ & 0.97 \\
\hline & $N-5-R-4$ & NW & $33 \cdot 51$ & 6.06 & $8 \cdot 21$ & $10 \cdot 05$ & $1 \cdot 23$ \\
\hline
\end{tabular}


Table 8. Continued

\begin{tabular}{|c|c|c|c|c|c|c|c|}
\hline Reference & Specimens & Concrete type & $f_{c}^{\prime}: M P a$ & $\rho f_{\mathrm{y}}: \mathrm{MPa}$ & v: MPa & $v_{\text {Equation } 10}$ & $v_{\text {Equation } 10} / v$ \\
\hline \multirow{21}{*}{ Sneed et al. (2016) } & $N-5-R-5$ & NW & $33 \cdot 51$ & 6.06 & $7 \cdot 45$ & $10 \cdot 05$ & $1 \cdot 35$ \\
\hline & $N-5-R-6$ & NW & $33 \cdot 51$ & 6.06 & $7 \cdot 45$ & $10 \cdot 05$ & $1 \cdot 35$ \\
\hline & $N-8-R-1$ & NW & $52 \cdot 06$ & 6.06 & $10 \cdot 34$ & 11.09 & 1.07 \\
\hline & $\mathrm{N}-8-\mathrm{R}-2$ & NW & $52 \cdot 06$ & 6.06 & $7 \cdot 79$ & 11.09 & $1 \cdot 42$ \\
\hline & $N-8-R-3$ & NW & $52 \cdot 06$ & 6.06 & 8.96 & 11.09 & $1 \cdot 24$ \\
\hline & S-SL-CJ-R-9-1 & LW & $37 \cdot 10$ & $4 \cdot 48$ & $6 \cdot 90$ & $8 \cdot 13$ & $1 \cdot 18$ \\
\hline & S-SL-CJ-R-9-2 & LW & $37 \cdot 10$ & $4 \cdot 48$ & 7.03 & $8 \cdot 13$ & $1 \cdot 16$ \\
\hline & S-SL-CJ-R-13-1 & LW & $38 \cdot 41$ & $6 \cdot 47$ & $8 \cdot 80$ & $9 \cdot 00$ & 1.02 \\
\hline & S-SL-CJ-R-13-2 & LW & 38.41 & $6 \cdot 47$ & $8 \cdot 27$ & $9 \cdot 00$ & 1.09 \\
\hline & S-SL-CJ-R-17-1 & LW & $34 \cdot 13$ & $8 \cdot 47$ & 8.69 & $9 \cdot 00$ & $1 \cdot 04$ \\
\hline & S-SL-CJ-R-17-2 & LW & $34 \cdot 13$ & $8 \cdot 47$ & $9 \cdot 10$ & $9 \cdot 00$ & 0.99 \\
\hline & S-SL-CJ-R-22-1 & LW & 34.48 & $10 \cdot 96$ & 8.96 & $9 \cdot 00$ & 1.00 \\
\hline & S-SL-CJ-R-22-2 & LW & 34.48 & $10 \cdot 96$ & 8.00 & $9 \cdot 00$ & $1 \cdot 13$ \\
\hline & S-CL-CJ-R-9-1 & LW & $32 \cdot 89$ & $4 \cdot 48$ & $5 \cdot 17$ & $7 \cdot 92$ & $1 \cdot 53$ \\
\hline & S-CL-CJ-R-9-2 & LW & $32 \cdot 89$ & 4.48 & $6 \cdot 76$ & $7 \cdot 92$ & $1 \cdot 17$ \\
\hline & S-CL-CJ-R-13-1 & LW & 31.99 & $6 \cdot 47$ & $7 \cdot 07$ & $9 \cdot 00$ & $1 \cdot 27$ \\
\hline & S-CL-CJ-R-13-2 & LW & 31.99 & $6 \cdot 47$ & $6 \cdot 53$ & $9 \cdot 00$ & $1 \cdot 38$ \\
\hline & S-CL-CJ-R-17-1 & LW & $31 \cdot 37$ & $8 \cdot 47$ & $7 \cdot 17$ & $9 \cdot 00$ & $1 \cdot 26$ \\
\hline & S-CL-CJ-R-17-2 & LW & $31 \cdot 37$ & $8 \cdot 47$ & $7 \cdot 93$ & $9 \cdot 00$ & $1 \cdot 14$ \\
\hline & S-CL-CJ-R-22-1 & LW & 39.92 & $10 \cdot 96$ & $7 \cdot 90$ & $9 \cdot 00$ & $1 \cdot 14$ \\
\hline & S-CL-CJ-R-22-2 & LW & $39 \cdot 92$ & $10 \cdot 96$ & $7 \cdot 41$ & $9 \cdot 00$ & $1 \cdot 21$ \\
\hline
\end{tabular}

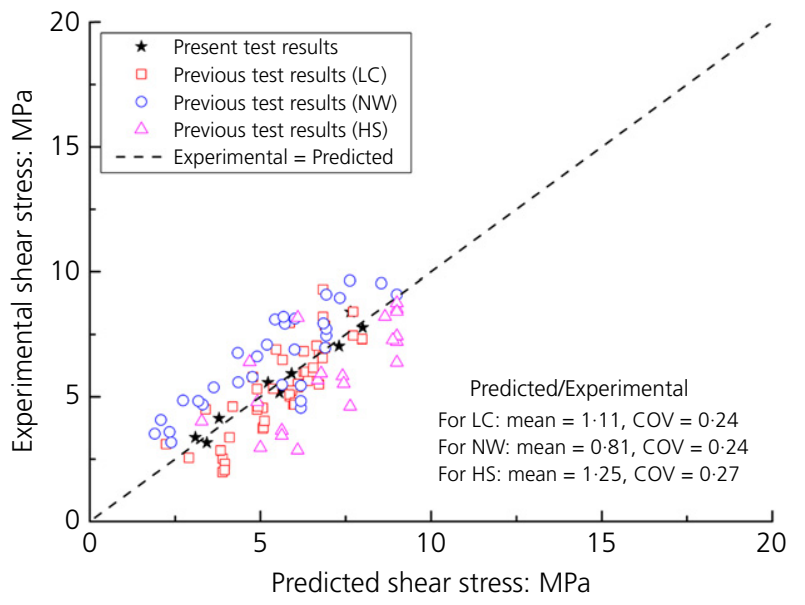

(a)

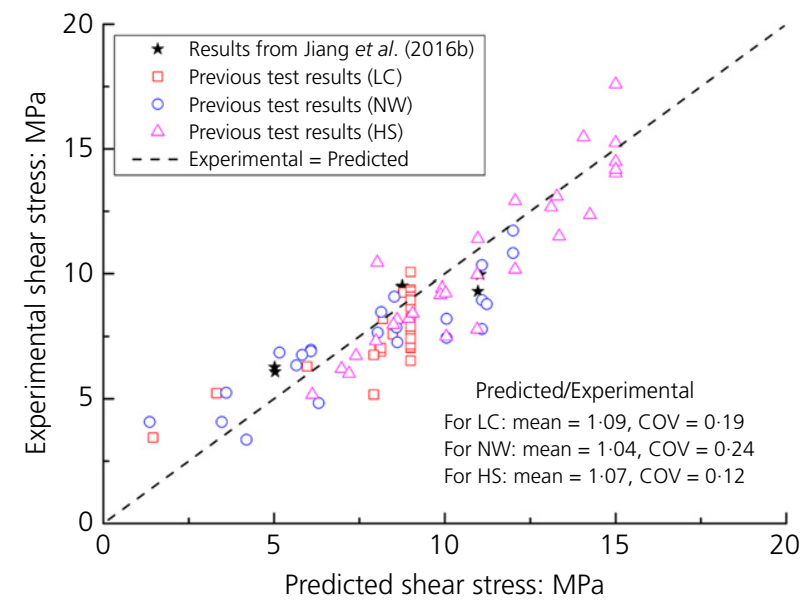

(b)

Figure 13. Evaluation of proposed shear resistance equation: (a) smooth interface condition; (b) rough interface condition

condition, the mean values of predicted to experimental results vary from 1.04 to $1 \cdot 09$, which demonstrates that Equation 10 can be potentially used to predict the interface shear capacity of NW, LW and HS concrete. However, the authors suggest that more push-off test data of interface shear resistance between HS and LW concrete are needed to verify the applicability of the proposed empirical equations.

\section{Conclusions}

Bridges constructed with precast HS concrete girders and LW concrete slabs have been widely used in many projects. Based on the results of this research, the main conclusions are drawn as follows.

(a) The main mechanism of failure modes for most specimens was shear along the shear plane, but with some splitting cracks around it.

(b) Both LW concrete strength and clamping stress made a very slight influence on cracking shear stress of the shear interface.

(c) The ultimate shear stress increased with increasing LW concrete strength, and increased significantly with increasing clamping stress. 
Table 9. Comparison of proposed equation with other researchers' experimental results

\begin{tabular}{|c|c|c|c|c|c|c|c|c|c|c|c|}
\hline \multirow{2}{*}{$\begin{array}{l}\text { Interface } \\
\text { condition } \\
\text { Smooth interface }\end{array}$} & \multirow{2}{*}{$\begin{array}{l}\text { Concrete } \\
\text { type } \\
\text { LW }\end{array}$} & \multicolumn{2}{|l|}{ Reference } & \multicolumn{2}{|c|}{ Mean } & \multicolumn{3}{|c|}{ Standard deviation } & \multicolumn{3}{|c|}{$\begin{array}{c}\text { Coefficient of } \\
\text { variation }\end{array}$} \\
\hline & & Mattock et al. (1976) & $0 \cdot 89$ & $1 \cdot 11$ & 1.04 & $0 \cdot 12$ & 0.26 & 0.31 & 0.14 & $0 \cdot 24$ & 0.29 \\
\hline & & Hoff (1992) & $1 \cdot 33$ & & & 0.27 & & & 0.21 & & \\
\hline & & Shaw and Sneed (2014) & 0.99 & & & 0.20 & & & 0.20 & & \\
\hline & & Sneed et al. (2016) & 1.07 & & & 0.12 & & & 0.11 & & \\
\hline & NW & Hofbeck and Ibrahim (1969) & $0 \cdot 76$ & $0 \cdot 81$ & & 0.14 & $0 \cdot 18$ & & 0.19 & $0 \cdot 23$ & \\
\hline & & Mattock et al. (1976) & $0 \cdot 71$ & & & 0.03 & & & 0.04 & & \\
\hline & & Kahn and Mitchell (2002) & 0.77 & & & 0.04 & & & 0.05 & & \\
\hline & & Shaw and Sneed (2014) & 1.06 & & & 0.21 & & & 0.20 & & \\
\hline & $\mathrm{HS}$ & Kahn and Mitchell (2002) & $1 \cdot 33$ & $1 \cdot 33$ & & 0.29 & 0.29 & & 0.22 & $0 \cdot 22$ & \\
\hline \multirow[t]{9}{*}{ Rough interface } & LW & Mattock et al. (1976) & 0.89 & 1.09 & 1.07 & 0.25 & 0.21 & 0.20 & 0.28 & 0.19 & 0.19 \\
\hline & & Shaw and Sneed (2014) & 1.09 & & & $0 \cdot 16$ & & & $0 \cdot 14$ & & \\
\hline & & Sneed et al. (2016) & $1 \cdot 17$ & & & $0 \cdot 14$ & & & 0.12 & & \\
\hline & NW & Mattock et al. (1976) & 0.85 & 1.04 & & 0.24 & 0.24 & & 0.29 & $0 \cdot 23$ & \\
\hline & & Mattock (1976) & 1.04 & & & $0 \cdot 19$ & & & $0 \cdot 18$ & & \\
\hline & & Mansur et al. (2008) & 1.06 & & & 0.11 & & & $0 \cdot 10$ & & \\
\hline & & Shaw and Sneed (2014) & $1 \cdot 28$ & & & 0.11 & & & 0.09 & & \\
\hline & $\mathrm{HS}$ & Kahn and Mitchell (2002) & 0.97 & 1.08 & & $0 \cdot 10$ & 0.13 & & $0 \cdot 10$ & $0 \cdot 12$ & \\
\hline & & Mansur et al. (2008) & $1 \cdot 14$ & & & $0 \cdot 10$ & & & 0.09 & & \\
\hline
\end{tabular}

(d) Specimens with higher clamping stress had higher residual shear stress, irrespective of LW concrete strength.

(e) Both interface vertical slippages and horizontal dilations at ultimate shear stress increased with increasing clamping stress, independent of LW concrete strength.

$(f)$ For the rough interface condition, Equations 2-5 gave unsafe predictions, with the value of predicted/ experimental results ranging from $1 \cdot 18$ to $1 \cdot 58$. In contrast, other equations discussed in this study underestimated the interface shear capacity. All the existing equations mentioned above represented conservative theoretical results for rough interface shear resistance between HS and LW concrete.

(g) A more accurate model based on multiple regression analysis of the test results of the authors was proposed and verified by other experimental results (Table 9). It can be used to predict the interface shear capacity well for LW, NW and HS concretes.

\section{Acknowledgements}

The research presented was funded by National Natural Science Foundation of China (51778150), Science and Technology Planning Project of Guangzhou City (201804010422), and Science and Technology Planning Project of Guangdong Province (2016B050501004). The authors gratefully acknowledge their generous support and declare that they have no conflict of interest.

\section{REFERENCES}

AASHTO (American Association of State Highway and Transportation Officials) (2015) AASHTO Bridge Design Specifications, 7th edn. AASHTO, Washington, DC, USA.

ACl (American Concrete Institute) (2014) ACI 318-14: Building code requirements for structural concrete. American Concrete Institute, Farmington Hills, MI, USA.
ASTM (2011) C 496/C 496M: Standard test method for splitting tensile strength of cylindrical concrete specimens. ASTM International, West Conshohocken, PA, USA.

ASTM (2014) C 469/C 469M: Standard test method for static modulus of elasticity and Poisson's ratio of concrete in compression. ASTM International, West Conshohocken, PA, USA.

ASTM (2015) C 1231/C 1231M: Standard practice for use of unbond caps in determination of compressive strength of hardened cylindrical concrete specimens. ASTM International, West Conshohocken, PA, USA.

ASTM (2017) C 138/C 138M: Standard test method for density (unit weight), yield, and air content (gravimetric) of concrete. ASTM International, West Conshohocken, PA, USA.

Bass RA, Carrasquillo RL and Jirsa JO (1989) Shear transfer across new and existing concrete interfaces. ACI Structural Journal 86(4): 383-393

Birkeland PW and Birkeland HW (1966) Connections in precast concrete construction. ACI Structural Journal 63(3): 345-368.

Hanson NW (1960) Precast-prestressed concrete bridges 2. Horizontal shear connections. Journal of the PCA Research and Development Laboratories 2(2): 38-60.

Harries KA, Zeno G and Shahrooz B (2012) Toward an improved understanding of shear-friction behavior. ACI Structural Journal 109(6): 835-844.

Hofbeck JA and Ibrahim IO (1969) Shear transfer in reinforced concrete. Journal of the American Concrete Institute 66(1) $119-128$.

Hoff GC (1992) High-strength lightweight aggregate concrete for arctic applications - part 3. In Structural Lightweight Aggregate Concrete Performance (Holm TA and Vaysburd AM (eds)). American Concrete Institute, Farmington Hills, MI, USA, SP-136, pp. $175-245$.

Jiang HB, Fang ZC, Ma ZJ, Fang X and Jiang ZW (2016a) Shear-friction behavior of groove interface in concrete bridge rehabilitation. Journal of Bridge Engineering 21(11): 04016081.

Jiang HB, Fang ZC, Liu AR, Li YH and Feng JH (2016b) Interface shear behavior between high-strength precast girders and lightweight cast-in-place slabs. Construction \& Building Material 128(C): 449-460

Kahn LF and Mitchell AD (2002) Shear-friction tests with high-strength concrete. ACI Structural Journal 99(1): 98-103. 
Kahn LF and Slapkus A (2004) Interface shear in high strength composite T-beams. PCI Journal 49(4): 102-110.

Kriz LB and Raths CH (1965) Connections in precast concrete structures - strength of corbels. PCI Journal 10(1): 16-61.

Kuchma DA and Nagle TJ (2007) Shear transfer resistance in high-strength concrete girders. Magazine of Concrete Research 59(8): 611-620.

Loov RE and Patnaik AK (1994) Horizontal shear strength of composite concrete beams with a rough interface. PCI Journal 39(1): 48-69.

Mansur MA, Vinayagam T and Tan KH (2008) Shear transfer across a crack in reinforced high-strength concrete. Journal of Materials in Civil Engineering 20(4): 294-302.

Mattock AH (1974) Shear transfer in concrete having reinforcement at an angle to the shear plane. ACI Structural Journal 42(2): $17-42$.

Mattock AH (1976) Shear Transfer under Monotonic Loading across an Interface between Concrete Cast at Different Times. University of Washington Department of Civil Engineering, Seattle, WA, USA, Report SM 76-3.

Mattock AH (2001) Shear-friction and high-strength concrete. ACI Structural Journal 98(1): 50-59.

Mattock AH and Hawkins NM (1972) Shear transfer in reinforced concrete - recent research. PCI Journal 17(2): 55-75.
Mattock AH, Johal L and Chow HC (1975) Shear transfer in reinforced concrete with moment or tension acting across the shear plane. PCI Journal 20(4): 76-93.

Mattock AH, Li WK and Wang TC (1976) Shear transfer in lightweight reinforced concrete. PCI Journal 21(1): 20-39.

Paulay T, Park R and Phillips MH (1974) Horizontal construction joints in cast-in-place reinforced concrete. In Shear in Reinforced Concrete. American Concrete Institute, Detroit, MI, USA, ACI Special Publication SP-42, vol. II, pp. 599-616.

Shaw DM and Sneed LH (2014) Interface shear transfer of lightweightaggregate concretes cast at different times. PCI Journal 59(3): $130-144$.

Sneed LH, Krc K, Wermager S and Meinheit D (2016) Interface shear transfer of lightweight-aggregate concretes with different lightweight aggregates. PCI Journal 61(2): 38-55.

Walraven JC (1981) Theory and experiments on the mechanical behavior of cracks in plain and reinforced concrete subjected to shear loading. Heron 26(1): 66-84.

Walraven J, Frénay J and Pruijssers A (1987) Influence of concrete strength and load history on the shear-friction capacity of concrete members. PCI Journal 32(1): 66-84.

Walraven JC and Stroband J (1994) Shear-Friction in High-Strength Concrete. American Concrete Institute, Detroit, MI, USA, ACI High-Performance Concrete SP-149, pp. 311-330. 